\title{
De las Building Societies al Crédito Recíproco: una aproximación al ahorro y préstamo para viviendas en Argentina, 1935-1949
}

\author{
Juan Lucas Gómez \\ Universidad de Buenos Aires
}

\section{Resumen}

Este artículo se enmarca dentro de una investigación que estudia la evolución del mercado de crédito para viviendas en Argentina entre 1930 y 1955 . En particular se ocupa de analizar el funcionamiento de las sociedades de Crédito Recíproco debido a su significativa gravitación en el mercado. A través de una mirada de largo plazo, el análisis reconstruye la influencia del modelo de las Building Societies anglosajonas tanto sobre el segmento de ahorro y préstamo para viviendas en Argentina durante la primera mitad de siglo como particularmente sobre las sociedades de Crédito Recíproco para caracterizar y problematizar la dinámica del sector.

Palabras clave

Crédito para viviendas; ahorro; crédito recíproco; swat; acuerdos bilaterales

Códigos JEL: D15, E21, g21, G51
FROM BUILDING SOCIETIES TO RECIPROCAL CREDIT: AN APPROACHTO SAVING AND HOUSE LOANS IN ARGENTINA, 19351949

\section{Abstract}

This article is part of an investigation that studies the evolution of the credit market for house in Argentina between 1930 and 1955. In particular, it deals with analyzing the functioning of operation of reciprocal credit companies due to its significant influnce on the market. Through a long-term look, the analysis reconstructs the influence of the model of the Anglo-saxon Bulding Society model both the savings and loans segment for house in Argentina during the first half of the century, particulary on reciprocal credit companies to guarantee and problematize the dynamics of the sector.

\section{Keywords}

Housing credit; savings; reciprocal credit; SWAP; bilateral arregements

JEL codes: D15, E21, g21, G51

Fecha de recepción del original: 3 de marzo de 2021; versión definitiva: 1 de junio de 2021.

Juan Lucas Gómez, Universidad de Buenos Aires, Facultad de Ciencias Económicas, CEEED / Universidad Nacional de Tres de Febrero, Argentina.

E-mail: odin835@hotmail.com. ORCID ID: https://orcid.org/0000-0002-1168-0350 


\title{
De las Building Societies al Crédito Recíproco: una aproximación al ahorro y préstamo para viviendas en Argentina, 1935-1949
}

\author{
Juan Lucas Gómez \\ Universidad de Buenos Aires
}

Introducción

Este artículo forma parte de una investigación sobre el funcionamiento del mercado de crédito para viviendas en Argentina durante el período de entreguerras. Con el objetivo de complementar anteriores trabajos, la pesquisa estudia las características del sistema de financiamiento aplicado por las empresas de Crédito Recíproco (CR). Esta fue la denominación que recibieron un conjunto de sociedades anónimas que, entre 1935 y 1949, aplicaron un modelo de ahorro y préstamo para viviendas que suprimía el juego de intereses inspirado en la experiencia de las sociedades mutualistas británicas conocidas como Building Societies (BS) (Capel, 2013). Consolidadas como uno de los actores más importantes del mercado de crédito, en 1949, la modalidad financiera fue prohibida, las compañías liquidadas, su cartera hipotecaria transferida al Banco Hipotecario Nacional (BHN) y los depósitos de los ahorristas a la Caja Nacional de Ahorro Postal (CNAP). Para mensurar la gravitación del sector en el mercado, vale destacar que la transferencia de su cartera a la órbita del BHN significó un aumento del $25 \%$ de las obligaciones de dicha institución?.

Si bien coyunturalmente dichas medidas estuvieron estimuladas más por la evolución de la economía nacional que por la dinámica de las empresas, a la vez, clausuraron más de una década de debates sobre el sector. Dichas discusiones se concentraron en resolver cuáles eran las políticas más adecuadas para promover el $\mathrm{CR}$, dado que las autoridades entendían que ofrecían un medio de capitalización de los trabajadores y las clases medias (lóvine, 1947; Pardo, 1947), y regular la actividad, pues, aunque las sociedades de CR estaban facultadas para recibir depósitos de terceros y entregar créditos no estaban alcanzadas por la ley de Bancos. También interpelaban dos problemas centrales del proceso sustitutivo: la necesidad

\footnotetext{
1 BHN, Memorias, 1949: 1-15.
}

de inversiones para la construcción de viviendas e infraestructura urbana capaz de alojar una población en aumento, lo que constituía un requisito central para la consolidación del mercado interno, y las dificultades del mercado de capitales local para ofrecer financiamiento de largo plazo.

En esa línea, si bien la construcción de viviendas para los trabajadores reunía un amplio consenso, tanto por sus efectos multiplicadores como por consideraciones sociales, la dificultad para canalizar las inversiones o generar nuevos ahorros creaban un cuello de botella para el desarrollo de las políticas necesarias (Fitte, 1942). En ese contexto, las discusiones sobre el denominado "problema de la vivienda" cobraron centralidad e interpelaron cada vez con más fuerza el segmento de sociedades de ahorro y préstamo y en particular a las de CR (Lercari, 1945). En términos teóricos, la posición favorable hacia el CR sostenía que estas sociedades podrían captar los ahorros de un sector población sin relación con el sistema financiero y, de esa manera, hacer crecer el mercado de capitales y facilitar el acceso a la vivienda a los trabajadores y las clases medias sin requerir recursos necesarios para desarrollar otras inversiones. Dicha línea, en rigor, proponía un medio para estimular a los trabajadores a generar ahorros, invertirlos en viviendas y, por esta vía, solucionar el déficit habitacional. Esta postura, por otra parte, trazaba un paralelismo con la experiencia de las BS anglosajonas y proyectaba las potencialidades del CR a partir de la actividad de dichas sociedades en Gran Bretaña y Estados Unidos (Lamas, 1950). Empero, quienes desconfiaban de las posibilidades del sector, se apoyaban en una larga tradición local de sociedades de ahorro y préstamo atravesada por dificultades para cumplir con los contratos y denuncias por prácticas irregulares (Pérez, 1944).

En efecto, como evidenciaremos en este trabajo, las sociedades de CR no sólo buscaron emular la experiencia de las BS anglosajonas, sino que se montaron sobre una importante experiencia previa en el mercado local vinculada al ahorro y préstamo. Para mediados de la década del treinta, cuando surgieron las firmas de CR, ni el déficit habitacional ni la formación de sociedades de ahorro y préstamo constituían una novedad en Argentina. De hecho, algunos aspectos centrales del crecimiento de las grandes ciudades a comienzos de siglo, y especialmente de Buenos Aires, fueron la consolidación del 
mercado de alquileres, en particular en las casas colectivas conocidas como conventillos, el predominio de los mecanismos de financiamiento informales, fundamentalmente asociados a los planes de pago ofrecidos por los rematadores de terrenos, y las prácticas de auto construcción, que a la postre darían origen a la tipología denominada como casa chorizo (Ballent y Liernur, 2014; Armus y Hardoy, 1990).

Los estudios clásicos de la historiografía urbana (Scobie, 1977; Walter, 1993; Yujnovsky,1974) también evidenciaron la temprana multiplicación de compañías de ahorro y préstamo dedicadas a financiar a los trabajadores, especialmente a partir del contexto de estabilidad monetaria generado por la puesta en marcha de la Caja de Conversión en 1901 y que se extendió hasta la Primera Guerra Mundial (Cortés Conde, 1979). Aunque la historiografía observó el crecimiento de este tipo de firmas, no identificó la temprana e importante influencia que el modelo de las BS ejerció en el mercado local. Ello resulta particularmente extraño debido a que tanto la prensa como algunos de los líderes más importantes del socialismo local, como Juan B. Justo, lo destacaron con cierta insistencia. De hecho, la cooperativa El Hogar Argentino (EHO) (Repetto, 1976; Ronchi, 2016), fundada por el Partido Socialista, así como algunas de las sociedades de ahorro y préstamo para viviendas más importantes y con mayor perduración en el mercado, como el Banco el Hogar Argentino (BHA) y la Buenos Aires Building Society (BABS), entre otras, se organizaron como $B S$ y reprodujeron dicho modelo con cierto éxito hasta 1914.

El impacto de la Primera Guerra Mundial significó un freno para la expansión económica y también para el mercado inmobiliario, que habría de recuperar cierto dinamismo durante la siguiente década. No obstante, la información brindada por la prensa y las guías de sociedades anónimas, indicaría un relativo retroceso de las estrategias de financiamiento señaladas consistente con la evolución del poder de compra de los salarios (Lanata Briones, 2020). Por su parte, las transformaciones provocadas por la crisis de 1929, al compás del avance del proceso sustitutivo y de aumento de la población urbana, crearon nuevamente un escenario de crecimiento de la demanda de viviendas que provocó la proliferación de nuevos canales de financiamiento enfocados en la vivienda obrera. En efecto, en la segunda mitad de la década, la recuperación de la actividad y la consolidación de salarios más regulares funcionaron como un estímulo del resurgimiento de los mecanismos de ahorro y préstamo. Al compás de dichos cambios, el mercado de crédito hipotecario atravesó por importantes cambios, aunque se mostró incapaz de cubrir la demanda de créditos (Gómez y Gilbert, 2019). De esta manera, el surgimiento de sociedades de CR se dio en un contexto de aumento de la demanda, que no era cubierta por el crédito bancario, se montaba sobre un modelo financiero, el de las BS, que contaba no sólo con una importante influencia a nivel internacional, sino también con una experiencia acumulada en el mercado local.

Tal como indican los procesos reseñados, a pesar del aumento del volumen de financiamiento durante la década del treinta el déficit habitacional se reactualizó y progresivamente se convirtió en unos de los problemas sociales que recibió mayor atención de los analistas durante el período (Bunge, 1940). Al mismo, las políticas públicas también diseñaron estrategias más agresivas, aunque no lograron estimular el crecimiento de la construcción en el volumen necesario (Calcagno, 1958). Una dimensión central para comprender estas dificultades, era que la solución del problema requería grandes inversiones debido a que la vivienda es una mercancía altamente dependiente del crédito. De hecho, esta dimensión económica, pero fundamentalmente crediticia, fue uno de los tópicos centrales de las discusiones sobre el denominado "problema de la vivienda" a lo largo del período analizado (Lamas, 1950). A pesar de ello, y quizás como consecuencia de que el enfoque dominante de la historiografía está colocado en el campo de la arquitectura, regularmente la literatura tiende a sugerir que los debates e iniciativas se concentraron casi exclusivamente en la promoción de modelos urbanos y tipologías de vivienda (Aboy, 2005; Ballent, 2005). Sin embargo, si se amplía el horizonte analítico es posible identificar una pluralidad de voces, que no excluía a los urbanistas, que sostenían que la cuestión fundamental era cómo obtener los recursos necesarios para financiar la construcción masiva (Fitte, 1942; Ferrer, 1945; Rottin, 1945). A la vez, la promoción de la industria de la construcción reunía cada vez más simpatizantes, como lo releva el frustrado Plan Pinedo de 1940 (Llach, 1984), debido a que sus efectos multiplicadores. Sobre ese escenario se montaron también otras voces que advertían, en una línea que pensamiento que recordaba la mirada de los higienistas, sobre las posibles consecuencias sociales derivadas de la falta de viviendas y de un crecimiento urbano desordenado (Aguilar, 2014).

No obstante, desde mediados de la década del treinta fueron cada vez más evidentes dos aspectos asociados al avance del déficit habitacional: el mercado de capitales no ofrecía el volumen de recursos necesarios y el nivel de los salarios dificultaba las posibilidades de que los trabajadores pudieran amortizar los valores requeridos por los prestamistas. En efecto, la producción de viviendas es una actividad que participa del proceso general de acumulación y valorización del capital, y los empresarios involucrados requieren una tasa de ganancia atractiva para invertir en el sector (Topalov, 1979; Yujnosky, 1984). Por su parte, los organismos públicos, como el BHN o la CNCB, orientaban sus políticas en otras direcciones a la vez que aún no habían atravesado por el proceso de transformaciones que les permitirían tener un protagonismo más decidido desde mediados de los cuarenta.

De esta manera, si bien la relación entre vivienda y políticas sociales resultó relativamente poco problemática de establecer, mucho más difícil fue resolver de dónde provendrían los capitales para financiar a los asalariados. Así, a pesar de las iniciativas y debates reseñados, aunque la oferta de financiamiento creció durante la década de 1930, no lo hizo en el volumen suficiente. Además, el mercado de crédito estuvo dominado por prestamistas particulares que operaban con hipotecas de corto plazo y bajos montos. En ese escenario, aún quienes podían acceder al financiamiento formal debían contar con importantes capitales propios para materializar las operaciones, pues el análisis de los Censo Hipotecarios Nacionales y de las principales líneas de financiamiento de las instituciones públicas indica que hasta la llegada del peronismo los créditos no cubrían más que el 50\% del valor de las operaciones (Gómez y Gilbert, 2019). 
En consecuencia, el crédito circulaba principalmente por canales informales lo que tendía a encarecer su costo y a generar importantes asimetrías entre quienes lograban acceder a los mecanismos formales y los que no. En ese contexto las empresas de CR ofrecían teóricamente, pero en algunos casos también empíricamente, aportar una porción significativa de las inversiones necesarias sin requerir financiamiento del mercado de capitales y, en particular, de los organismos públicos. En este plano, la estrategia era simple y consistía en generar círculos de ahorro cuyos préstamos serían invertidos en créditos hipotecarios para los asociados una vez que hubieran depositado a través de cuotas periódicas el equivalente al $20 \%$ de la vivienda que planeaban comprar o construir (Gómez, 2015).

Sectorialmente, además, los empresarios involucrados en el CR buscaron vincular sus actividades con objetivos sociales. Los argumentos destacaban su relación con la vivienda obrera, la oferta de créditos baratos y la lucha contra las prácticas especulativas derivadas de la falta de instituciones formales de crédito. Además, se le atribuía valores pedagógicos y moralizantes tanto a la práctica del ahorro y como a la propiedad de la vivienda. Pero si dicho discurso resultó operativo, en la medida en que diferentes decretos reglamentarios otorgaron facilidades al sector bajo supuestos similares, fue en buena medida debido a que las compañías de CR lograron instalarse como la adaptación criolla del modelo propuesto por las BS.

Lo que interesa destacar es que aunque es indudable que no existió una relación lineal entre el desarrollo internacional de las BS y su implementación en la Argentina, es igualmente cierto que tanto para los empresarios que impulsaron el CR, como para los funcionarios encargados de reglamentar la modalidad, dicha experiencia fue un aspecto importante de sus perspectivas. En función de ello, este capítulo propone describir someramente la historia de las BS, y de las primeras adaptaciones en Argentina, para reponer las características del CR. En ese sentido, una posible explicación sobre la ausencia de trabajos historiográficos sobre el CR deriva de su identificación como compañías loteo y financiamiento. Al incorporar su vínculo con las BS, la imagen se vuelve más compleja y puede contribuir a comprender mejor tanto su importancia como su dinámica. En este punto, a pesar de que no contamos con trabajos historiográficos, existe una importante cantidad de bibliografía contemporánea que permite caracterizar el sector y valorizar su gravitación tanto en el mercado de crédito como en los debates sobre las políticas públicas. En ese contexto, este artículo busca reponer las características del CR y especialmente las estrategias de los empresarios involucrados para avanzar en el estudio del funcionamiento del mercado de crédito para viviendas durante el período clásico de industrialización sustitutiva en Argentina.

Como ya se ha señalado, el presente artículo estudia el sistema de ahorro y préstamo aplicado por las sociedades de $C R$ y está compuesto por cuatro apartados. El primero repone la historia de las BS como punto de partida para comprender la naturaleza del sector y para evidenciar su influencia en las sociedades de ahorro y préstamo. El segundo, analiza la evolución del segmento de ahorro y préstamo inspirado en el modelo de las BS durante la primera mitad del siglo XX con el objetivo de reponer, en términos generales, la historia del mercado local antes del surgimiento del CR. El apartado final, por su parte, estudia la emergencia de las sociedades $C R$, su modelo de funcionamiento y características generales.

El argumento general del artículo sostiene que las sociedades de CR buscaron cubrir la demanda de crédito de los sectores trabajadores a través de la adaptación de un sistema de ahorro y préstamo de origen mutual que combinaba objetivos económicos con otros sociales. A la vez, indica que la identificación de la vinculación entre las sociedades de CR y las BS anglosajonas permite comprender mejor tanto la evolución del segmento de sociedades de ahorro y préstamo en Argentina, así como las discusiones y tensiones que la evolución de las empresas de CR provocó. En este punto, la hipótesis sostiene que buena parte de las facilidades que el organismo encargado de regular al sector, la Inspección General de Justicia (IGJ), otorgó derivaban de la identificación de su vínculo con las BS $y$, por lo tanto, con cierta asociación entre actividad empresarial y objetivos sociales. Dada la extensión del artículo, este último aspecto será objetivo de futuros trabajos.

\section{Las Building Societies}

El origen de la modalidad se remonta a 1775 con la formación de una sociedad mutual de edificación en Birmingham, Inglaterra (Bellman, 1927). Luego la experiencia habría de multiplicarse y difundirse en Gran Bretaña y EE.UU. Constituidas inicialmente como sociedades mutualistas de construcción, las BS crecieron a partir de mediados del siglo XIX hasta convertirse en uno de actores más importantes del mercado hipotecario durante las décadas de 1920 y 1930 tanto en Inglaterra (Samy, 2008) como en Estados Unidos (Whithe, Snowden y Fishback, 2014). En función de dicho crecimiento el sector tuvo un lugar central en los debates sobre la vivienda obrera en Europa entre finales del siglo de XIX y comienzos del XX (Gravagnuolo, 2010), especialmente entre los intelectuales ligados al movimiento socialista y al cooperativismo al punto que tanto Engels (1896) como Gide (1913) dedicaron una parte importante de sus esfuerzos a analizar las posibilidades del modelo.

Como se ha señalado, las BS surgieron como un desprendimiento de las instituciones de autoayuda conocidas como sociedades de amigos (Thompson, 2012), a las que debieron buena parte de sus miembros originarios (Boleat, 1981). Al mismo tiempo, formaron parte del proceso multiplicación de instituciones de financiamiento de escala local que se consolidó en Gran Bretaña a fines del siglo XVIII. Si bien, buena parte de la red de crédito estuvo dominada por la banca regional otras instituciones como las cajas de ahorro y las cooperativas de construcción tuvieron un rol preponderante (Cameron, 1974). Sin embargo, según sostiene Topalov (1984), aunque las BS estuvieron ligadas a la multiplicación de instituciones de crédito en rigor se constituyeron menos como sociedades financieras que de consumo colectivo. 
Específicamente las condiciones para el desarrollo de las BS fueron creadas por el avance de la economía de mercado, que dio lugar a un proceso de privatización y encarecimiento del suelo urbano, y de la industrialización que transformó la fisionomía de las ciudades. En efecto, la concentración de las actividades industriales en urbes carentes de la infraestructura necesaria derivó en la localización de los trabajadores en zonas dominadas por el hacinamiento y la miseria. La determinación de establecer factorías próximas al lugar de extracción de la materia prima, la generación de energía, o la salida de los bienes de intercambio, dio origen a desordenados asentamientos donde vivían los obreros, levantándose los llamados 'slums' (Hobsbawn, 1982). En simultáneo, la población que migró hacia las ciudades, pronto superó la infraestructura existente y condujo a que los barrios obreros fuesen levantados en condiciones miserables que llevarían a diferentes analistas a definir la vida de los obreros en las ciudades industriales como un "purgatorio terrenal" (Polanyi, 2011).

Si bien estas condiciones fueron objeto de malestar, rápidamente recuperado por la literatura, bajo el predominio de una economía liberal, la escasez de viviendas no era motivo suficiente para construirlas sino se podía garantizar su rentabilidad, pues para comienzos del siglo XIX se consolidó, de forma más generalizada, como una mercancía a la que accedía a través de los mecanismos de mercado. La puesta en marcha del mercado inmobiliario se consolidó a partir de las transformaciones que se produjeron en el régimen de tenencia con la consolidación de la propiedad privada que habría de significar el quiebre de otras formas comunales de tenencia. En este sentido, si la apropiación privada del suelo y la construcción fueron los dispositivos esenciales de la producción de la vivienda como mercancía, el crédito fue el mecanismo que históricamente explicó su adquisición (Capel, 2013). En esa línea, la asignación del crédito tuvo un rol prioritario tanto para la definición de las condiciones habitacionales como el acceso a la propiedad.

Desde el punto de vista de los nuevos trabajadores urbanos la cuestión era simple, debido a su costo, la propiedad de la vivienda estaba fuera de su alcance lo que los obligaba a vivir en condiciones deplorables y pagando elevados alquileres. Por su parte, los mecanismos de asignación del mercado no hacían más que agravar estas dificultades. En ese sentido, Topalov (1984) sostiene que las BS constituyeron un caso típico de las primeras iniciativas que se organizaron como una respuesta comunitaria frente al avance de la economía de mercado buscando recrear, en las nuevas condiciones, formas de consumo no mercantilizadas más ligadas a las estructuras sociales pre capitalistas. Dicha filiación permitiría identificar algunos de sus elementos más característicos: la organización mutual basada en relaciones comunitarias y en el principio de reciprocidad como eje articulador de los objetivos del grupo (Polanyi, 2011). En efecto, las primeras BS buscaban garantizar el acceso a la vivienda no a través de la compra individual sino de los ahorros colectivos de un grupo que se constituía a tal fin (Boleat, 1981).

El funcionamiento de estas primeras BS era relativamente sencillo. Se organizaban círculos de ahorro de número fijo y restringido al núcleo fundador, habitualmente vecinos de una misma parroquia, que se obligaban a pagar una cuota periódica con el propósito de que todos los socios pudieran acceder a una vivienda. Una vez acumulado los recursos necesarios se iniciaban las construcciones y progresivamente se iban entregando por turnos según diferentes criterios. Cuando todos los integrantes accedían a una casa, cuyo costo representaba el equivalente a la suma de todos los depósitos de un período de ahorro, la sociedad cumplía sus objetivos y se disolvía, motivo por el cual posteriormente estas instituciones fueron denominadas como "temporales" (Price y Walter, 2016).

Durante el período que mediaba entre el primer depósito y la entrega de la última vivienda no se incluía el juego de intereses, pues los socios no requerían otra remuneración más que el acceso a una vivienda. Usualmente las sociedades no se ocupaban solamente de reunir los capitales sino también de urbanizar los terrenos y construir las casas, incluso normalmente la fundación de una sociedad estaba atada a la propuesta de construir en un terreno específico (Lamas, 1950). A la postre, la capacidad para edificar se convirtió en una de las piedras angulares de las simpatías que las BS despertaron. Progresivamente, de hecho, las discusiones especialmente en el caso de intelectuales vinculados al cooperativismo estuvieron en buena medida subordinadas a su capacidad para materializar obras (Gide, 1932). Por otra parte, el funcionamiento descripto, contribuye a reforzar la idea de Topalov que sostiene que las primitivas BS no buscaban realizar negocios inmobiliarios sino garantizar el acceso a la vivienda como bien de uso a través de mecanismos consumo colectivos. Pero, además, también indicaría la existencia ciertos lazos de vecindad y reciprocidad como elementos cohesionadores del grupo, pues habitualmente se trataba de vecinos de la misma parroquia.

Como se ha señalado, habitualmente la historiografía sostiene que la primer BS se habría fundado en 1775 en la ciudad de Birmingham, Inglaterra. Sin embargo, es posible que se hubieran creado otras previamente dado que es muy difícil establecer los límites entre las primitivas BS y las sociedades de amigos. También es problemático determinar su número hasta finales del siglo XVIII, aunque es posible suponer que oscilaba entre 20 y 50. Lo cierto es que el movimiento se expandió con gran velocidad durante las primeras décadas siglo XIX primero por la región central y norte de Inglaterra y luego por el resto del país y Escocia. Para 1825 existían unas 250 BS que acumulaban unas 2000 viviendas construidas. Hacia esa época, además, algunas instituciones incorporaron a su funcionamiento la compra de casas. Para 1836, cuando se sancionó la primera ley que reguló a las BS y las separó del universo de sociedades amigos, existían unas dos mil instituciones en Gran Bretaña (Boleat, 1981).

Dicho éxito impulsó la formación en 1831 de la Previsora de Oxford en Estados Unidos, pues sus actas constitutivas indicaban expresamente la voluntad de replicar la experiencia británica (Martín, 1943). La sociedad fue organizada por S. Gilling y G. Harrocks, empresarios británicos ligados a la industria textil en Pensilvania. Sus estatutos señalaban que la sociedad se disolvería una vez alcanzados a todos los socios, pero también que entonces se dispondría del reparto de los beneficios lo que implicaba que se incluía el juego de intereses y el reparto de ganancias financieras (Martín, 1943). A través de este modelo 
de funcionamiento, las BS se extendieron siguiendo el patrón de migración de la población. Por su parte, el sector adoptó el nombre de Asociaciones de Ahorro y Préstamo (AAP) lo era consistente con el progresivo abandono de las construcciones directas y su concentración en el financiamiento de la compra venta (Price y Walter, 2016).

Hacia 1850 existían unas 2000 instituciones en Gran Bretaña y más de 250 de EEUU (Lamas, 1950). Desde entonces el sector continuó su expansión, en ambos márgenes del atlántico, asociadas al crecimiento de la economía industrial y la consolidación de salarios más regulares, así como a la falta de canales de financiamiento para los trabajadores. Para entonces, además, en el marco de las discusiones sobre las condiciones habitacionales de las ciudades industriales, que cobraron mayor intensidad a partir de 1840 especialmente en Europa, las políticas aceptaban el predominio del mercado en la asignación de recursos pero progresivamente, en el caso de los trabajadores, también se apuntaba a la filantropía ${ }^{2}$ y a la autoayuda.

En ese contexto se desarrollaron una serie de mutaciones muy importantes en los objetivos de las sociedades, pues abrieron el camino hacia operatorias que implicaban su transformación en asociaciones de ahorro y préstamo con un funcionamiento similar al de la banca hipotecaria (Bodfish, 1931). Si bien dichos cambios son difíciles de datar debido a la disponibilidad de fuentes, la historiografía tiende a señalar que se trató de un fenómeno simultáneo en Inglaterra y Estados Unidos y lo identifica como el surgimiento de las sociedades "permanentes" (Price y Walter, 2019).

Estas instituciones, tal como lo sugiere su denominación, no limitaban su actividad al núcleo de socios fundadores, sino que trabajaban a través de la emisión de series de ahorro y préstamo sucesivas e independientes. La clave de este sistema, denominado habitualmente como "plan serial", era que admitía que cada uno de los grupos funcionara con independencia de los otros de manera que las diferentes series formaban una suerte de asociación a plazo fijo individual. Ello permitía que las instituciones no se disolvieran cuando cumplían los objetivos de cada subgrupo (Lamas, 1950).

Además, este sistema admitía la afiliación de socios sin derecho a préstamo y separaba a los depositantes entre quienes pautaban al momento del ingreso un crédito futuro, acuerdos que se identificaron como "planes contractuales", y los que sólo cobraban intereses por los capitales invertidos contra las hipotecas con las que las sociedades garantizaban sus préstamos. Pero para cubrir dichos los intereses era necesario cobrarlos a quiénes buscaban financiamiento para comprar una vivienda. Dado que ello implicaba incluir el juego de intereses, las sociedades también distribuían utilidades sobre las acciones suscriptas que, en el caso de los socios pretendientes de

\footnotetext{
2 Las primeras las iniciativas de edificación popular, construidos en los bordes de las implantaciones manufactures o mineras, corrieron a cargo de empresarios filántropos influidos por una mirada más de corte humanitario que fue una parte fundamental para sentar las bases del pensamiento reformista. Estas iniciativas estuvieron acompañadas por la publicación de una serie de encuestas y estudios, como los de Chadwick en 1842 en Inglaterra o Villarmé dos años antes en Francia, que desnudaban la cruda situación habitacional de los obreros tal como también denunciaba Engels en 1845. Ver Blat, 2000
}

un crédito se depositaban a su favor acelerando el período de acumulación previo a la adjudicación del crédito. (Benes, 1966). Aunque este funcionamiento se asimilaba al de la banca hipotecaria quienes incluían a las BS dentro del movimiento cooperativo, como Charles Gide, sostenían que estas transformaciones permitían "el gran obstáculo con que tropieza la sociedad cooperativa de construcciones [...], el cual consiste en la imposibilidad de procurarse el capital necesario por medio de las simples suscripciones de los socios" (Gide, 1913: 267 y Gide, 1932: 799).

Lo cierto es que, si bien las transformaciones reseñadas permitían acelerar los plazos de entrega de los créditos también ponían en cuestión el principio de reciprocidad de las primeras instituciones a término. De hecho, el funcionamiento de las "sociedades permanentes" incluía dos operaciones independientes y con objetivos diferentes e implicaba cierta apertura al mercado de capitales. En este punto se concentraron los ataques provenientes del marxismo que sostenía que las BS no eran más que instituciones financieras destinadas a aumentar la renta urbana (Engels, 1986; Blat, 2000). Como una respuesta indirecta a dichas críticas, los estudios de casos sobre las distintas sociedades, regularmente encargados con fines celebratorios, identifican sus fundaciones con objetivos desinteresados y destacan los valores filantrópicos de sus iniciadores (Samy, 2008).

La articulación con el mercado de capitales resultó especialmente exitosa en la ciudad de Filadelfia, Estados Unidos. Desde mediados de siglo las asociaciones de la región aplicaron un modelo, denominado Plan Filadelfia, que combinaba sus préstamos con los de otras instituciones de crédito. Los socios aspirantes a un crédito debían ahorrar a través de cuotas periódicas un $20 \%$ del valor de la vivienda que deseaban comprar, luego la sociedad negociaba otro $50 \%$ a través de préstamos bancarios garantizados en primeras hipotecas y finalmente financiaba el 30\% restante con segundas hipotecas. Según señalan Price y Walter (2016), este sistema fue uno de lo que elementos que contribuyeron a convertir a Filadelfia en una ciudad con un alto número de propietarios en comparación con otras urbes en Estados Unidos. De hecho, Gide estimaba que las AAP habían financiado la construcción de unas 60000 casas en Filadelfia, a la que denominaba como "Ciudad de las Viviendas" (Gide, 1913: 268).

Durante la década de 1880 surgió otro modelo impulsado por la Asociación Mutual de Ahorro y Préstamo de Dayton, Ohio, y que sería el que Juan B. Justo propuso emular con la creación de EHO en Argentina. El sistema permitía a los socios abrir cuentas individuales sin una relación de dependencia con los otros depositantes ni obligación de realizar pagos sistemáticos. Ello permitía que se pudiera entrar o salir de la sociedad en cualquier momento sin la obligación de cubrir pagos atrasados o futuros. Si bien este plan no exigía regularidad en los depósitos tampoco obligaba a las sociedades a entregar créditos lo que eliminaba los "planes contractuales" (Benes, 1966). En efecto, una vez acumulada una cantidad determinada de aportes los ahorristas podían solicitar un préstamo, pero la sociedad no estaba obligada a entregarlos. Por su parte, el sistema incluía el juego de intereses y las utilidades se distribuían como saldo de cuenta. Este nuevo modelo, po- 
pularizado como Plan Dayton, impulsó la expansión del sector y la creación de las sociedades denominadas como "nacionales" en función de su alcance geográfico (Lamas, 1950). Estas instituciones funcionaban de una manera muy similar a las empresas hipotecarias, lo que no sólo las colocó en una competencia más directa con la banca, sino que además generó una separación aún más marcada respecto del funcionamiento originario.

Si bien la literatura describe las transformaciones reseñadas como una transición desde las sociedades "a término" hacia las "permanentes", en rigor ni se trató de un proceso lineal ni desaparecieron el primer tipo de instituciones. En la práctica convivieron sociedades que, aunque se identificaban bajo la denominación genérica de BS, tenían objetivos y prácticas diferentes. De hecho, a los distintos modelos financieros se sumaban otras importantes diferencias. Por ejemplo, mientras algunas sociedades se ocupaban de la urbanización y las edificaciones otras se concentraban sólo en los aspectos crediticios. En el mismo sentido, existían distintos modos de tenencia de las casas tanto en lo que se refiere a la propiedad cooperativa frente a la individual como entre esta última y el régimen de alquileres. Justamente esta pluralidad de experiencias llevó a Gide a sostener que "[...] la organización de estas sociedades es muy complicada" (Gide, 1932: 800).

Lo cierto es que hacia finales del siglo XIX la denominación de BS contenía una multiplicidad de prácticas diferentes. Esta heterogeneidad permite comprender mejor las diferentes perspectivas de análisis. Para los investigadores ligados al sector como Bellman (1927) y Bodfish y Theobald (1940) se trataba de instituciones de crédito organizadas para facilitar el acceso a la vivienda a los trabajadores. Este tipo de lectura, paulatinamente, se articuló con las posiciones reformistas que, sobre la base de plantear las relaciones sociales en una clave más armónica que antagónica, entendían un desarrollo urbano más equilibrado podría convertirse en un medio para construir sociedad más justa. Un ejemplo de esta perspectiva fue la estrecha relación que se estableció entre las BS y los promotores del modelo de las ciudades jardín de Howard (Dines, 2016). También algunos intelectuales cercanos al cooperativismo, como Gide, tenían una opinión favorable y vinculaba al sector más "las instituciones de progreso social" que con el universo financiero. Una mirada opuesta ofrecía el marxismo. Así, en su clásico trabajo sobre la vivienda, Engels sostenía que las BS "[...] ni son sociedades obreras ni su finalidad principal es procurar a los obreros casas que les pertenezcan en propiedad" sino compañías que incrementar la renta urbana capturando la porción que no se extraía a través de los alquileres ${ }^{3}$.

\footnotetext{
3 “[...] las pequeñas sociedades que iniciaron el negocio no lo tienen menos que sus grandes imitadores. En alguna taberna (y generalmente por instigación del dueño) donde luego celebrarán las reuniones semanales los clientes habituales y sus amigos, tenderos, dependientes, viajantes de comercio, artesanos y otros pequeños burgueses ( $y$ de vez en cuando un obrero constructor de máquinas u otro de los que forman parte de la aristocracia de su clase) se agrupan en una cooperativa para la construcción de casas. El pretexto inmediato suele ser el hecho de haber descubierto el dueño de la taberna un solar en venta por un precio relativamente bajo, en la vecindad o en sitio cualquiera. Los miembros, en su mayoría, no están ligados a un lugar fijo por sus ocupaciones; incluso numerosos tenderos y artesanos no tienen en la ciudad más que un local comercial y ninguna vivienda. En cuanto puede, cada uno de ellos prefiere vivir en las afueras más bien que en la ciudad ahumada. Se compra
}

En líneas generales, la historiografía contemporánea evidencia el predominio de los sectores medios en la administración de las sociedades, pero también una fuerte relación entre las BS y la vivienda obrera (Mason, 2004). No obstante, las investigaciones sugieren, tanto para el caso británico (Samy, 2008) como el norteamericano (Price y Walter, 2019), que las BS financiaron a los trabajadores con mejores y más regulares salarios. Temporalmente estos debates se concentraron en las últimas décadas del siglo XIX y las primeras del XX porque que durante dicha etapa las BS tuvieron un rol destacado en el proceso de expansión de los suburbios en el mundo anglosajón (Scott, 2008; Hobsbawn, 2003). De hecho, hacia 1929 existían 1026 sociedades en Gran Bretaña y 12342 en Estados Unidos (Lamas, 1950: 87-88).

Por otra parte, a mediados de la década del veinte, surgieron en Alemania las denominadas Cajas de Ahorro para la Edificación (CAE). Estas instituciones, que fueron las que los promotores de CR buscaron adaptar en Argentina, operaban con planes contractuales y sin cobrar intereses por los préstamos ni computarlo a los ahorros. Esta estrategia provocó que los plazos de entrega de los créditos se extendieran, pues los recursos dependían de la capacidad de pagos de los subscriptores. Para atraer a nuevos clientes muchas sociedades garantizaban en sus publicidades plazos precisos de entrega de los créditos, aunque no contaban con elementos más que sus propias proyecciones para cumplir con sus ofertas y para cumplir con lo pautado era necesaria la incorporación de nuevos socios. En consecuencia, las autoridades reglamentaron las publicidades y contratos para evitar prácticas engañosas y también se prohibió que las sociedades utilizaran en sus denominaciones referencias al "crédito sin interés", cuando cobraran cuotas de administración (Gualindo Guarneros, 1962).

Hacia mediados de la década del treinta las CAE atravesaron una crisis de liquidez que dio lugar a una serie de reformas que incluyeron la inclusión la apertura al mercado de capitales y el cobro de intereses. Básicamente las CAE aplicaron un modelo similar al Plan Filadelfia. A pesar de estas transformaciones, los problemas de liquidez continuaron y finalmente en 1938 el gobierno sancionó leyes establecieron un freno al sector (Gualindo Guarneros, 1962).

La década de 1930 también fue una etapa de profundas transformaciones para las BS anglosajonas, como resultado del impacto de la crisis de 1929. En Estados Unidos en 1930 fueron liquidadas unas 1700 sociedades, afectadas por el aumento de mora y el retiro de capitales. Inicialmente las sociedades se

el solar y se construye en él el mayor número de cottages. El crédito de los más acomodados hace posible su compra, mientras que las cotizaciones semanales, además de algunos pequeños empréstitos, cubren los gastos semanales de la construcción. Los miembros que proyectan la adquisición de la propiedad de una casa reciben por sortero sus cottages a medida que se van terminando, y lo que pagan como suplemento del alquiler permite la amortización del precio de la compra. Los otros cottages se alquilan o se venden. En cuanto a la sociedad de construcción, cuando hace buenos negocios, constituye fortuna más o menos importante que pertenece a sus miembros en tanto éstos siguen efectuando el pago de sus cotizaciones, y se reparte entre ellos de en cuando o a la disolución de la sociedad. De cada diez sociedades de construcción inglesas, nueve viven así. Las otras son más importantes y se crean a veces con pretextos políticos o filantrópicos. Pero su finalidad principal es siempre ofrecer a la pequeña burguesía una mejor inversión de sus ahorros en hipotecas con un buen interés, y con la perspectiva de dividendos gracias a la especulación en bienes raíces" (Engels, 1986: 80-82). 
protegieron a través de ejecuciones hipotecarias, al punto que dicho rubro pasó a representar un $20 \%$ de los activos totales del sector para mediados de la década. No obstante, la caída en los precios de las viviendas colocó también un límite a esta estrategia defensiva (Price y Walter, 2016). Finalmente, la salida de la crisis llegó de la mano de un programa de rescate del Gobierno y la creación de nuevo marco institucional conocido como "federalización" (Snowden, 2003). En 1932 se creó el Sistema Federal de Bancos de Préstamos Sobre Viviendas que tenía como objetivo sanear el mercado hipotecario. Un año después, se creó una corporación pública que transformó las hipotecas depreciadas en créditos más largos y baratos lo que permitió frenar las ejecuciones y depurar las carteras hipotecarias. En 1934 se sumó la Administración Federal de la Vivienda que, a cambio de asegurar los créditos, imponía criterios para orientar su asignación. Si bien la intervención del gobierno permitió sanear el mercado, algunos estudios argumentan que la federalización implicó un frenó para la actividad de las AAP y la organización de nuevo sistema en el que dichas sociedades comenzaron a funcionar de forma muy similar a la banca hipotecaria (Martín, 1966).

Por otra parte, lo que interesa señalar es que la expansión de las BS, y especialmente el protagonismo que el sector alcanzó a finales del XIX y mantuvo durante el período de entreguerras, inspiró buena parte de las iniciativas vinculadas al ahorro y préstamo para la vivienda en Argentina y especialmente en el caso de las sociedades de CR. En este sentido, si bien no existió una relación lineal entre la evolución internacional de las BS y sus adaptaciones en la Argentina, es igualmente cierto que esas experiencias contribuyeron a moldear el prisma a través del cual se leían los problemas y posibilidades del mercado local. De esta manera, tanto la primera expansión del mercado argentino a comienzos de siglo, así como la dinámica del CR durante la década del treinta son difíciles de comprender sin considerar las experiencias reseñadas.

Las Building Societies en Argentina

El proceso de expansión económica registrado durante las dos últimas décadas del siglo XIX provocó una acelerada transformación urbana. Resultado de dicha dinámica, y producto de la concentración de las actividades, fue la radicación de un creciente número de trabajadores en las áreas metropolitanas en forma precaria, en piezas de inquilinato o en conventillos (Scobie, 1977). Si bien un aspecto dominante del negocio inmobiliario en este período fueron los alquileres en las zonas céntricas, la extensión de la red tranviaria y su electrificación permitieron incorporar al espacio urbano tierras ubicadas en áreas periféricas que dieron lugar al desarrollo de nuevos negocios. Básicamente el loteo y la venta a plazos por parte de promotores y empresas que en buena medida funcionaban también como intermediarios entre el crédito formal y el informal ${ }^{4}$.

Se trataba no sólo de la especulación con terrenos céntricos sino también de la producción de lotes ubicados en los espacios intersticiales, que separaban los "centros" de los pueblos vecinos, y que posteriormente terminarían integrándose como barrios. En sentido, la expansión de Buenos Aires, pero también de otras grandes ciudades como Rosario, implicó un proceso de incorporación de tierras y creación de canales de financiamiento que incluyó diferentes actores, como bancos, compañías de transportes, propietarios de tierras terrenos, rentistas, rematadores y sociedades financieras (Lanciotti 2009). Por su parte, el sector público no ocupó un rol importante en el mercado de crédito para viviendas y, en general, las inversiones se orientaron en otras direcciones. Si bien en 1904 el BHN incluyó una línea de crédito para viviendas, se trató de una operatoria que ocupó un lugar marginal (BHN, 1986). Ello respondía a una orientación de las políticas públicas que tendía a reforzar los mecanismos de asignación del mercado.

No obstante, a comienzos de siglo la estabilidad monetaria generó un contexto favorable para el crecimiento la oferta de créditos y contribuyó a consolidar a las hipotecas urbanas como una inversión no sólo segura sino muy rentable, al punto que el mercado local pagaba mayores intereses que la plaza europea. Dicha coyuntura posibilitó también que se redujera la proporción de inquilinos y de ocupación de los conventillos sobre la base de una flexibilización de las tasas de interés y mensualidades pagadas por los lotes (Yujnovsky, 1974: 360372).

En ese escenario se multiplicaron las sociedades anónimas financieras, incluso con participación de capitales extranjeros, que actuaban en la compra-venta de lotes urbanos. El crecimiento del mercado contó con una diversidad de protagonistas y en muchos casos se asoció también a prácticas informales. Una mirada panorámica del sector revela que muchas de estas sociedades tuvieron un comportamiento errático ${ }^{5}$. Las

\footnotetext{
4 De esta manera, regularmente, el camino hacia la propiedad de la vivienda, en los casos en que era posible, comenzaba con la compra de un lote en cuotas y luego las edificaciones corrían a cargo del grupo familiar que progresivamente iba adicionando habitaciones conforme las posibilidades y la incorporación de nuevos integrantes lo permitían y hacían necesario. Esta dinámica respondía no sólo a la abundancia de terrenos sino fundamentalmente a la demanda de viviendas por parte de los nuevos habitantes urbanos que, progresivamente, construyeron una cultura que vinculaba la movilidad social ascendente con la propiedad de la vivienda (Armus y Ardoy 1990). $\mathrm{Si}$, por un lado, ello dio lugar a una tipología urbana denominada casa "chorizo", por otro consolidó la estrategia de la casa autoconstruida que vinculaba la propiedad a una ética del ahorro y el sacrificio. (Liernur, 1984)

5 “Hacia 1914, el Tercer Censo Nacional registra la existencia en todo el país de 11 sociedades de préstamos, construcciones y compra-venta de inmuebles ( 16,4 del total de sociedades), que reúnen el $13,6 \%$ del total de capital emitido por sociedades anónimas. El auge tuvo lugar especialmente a partir de los primeros años del siglo. Una de las sociedades más importantes que actúan en el mercado inmobiliario, por ejemplo, el Banco de Préstamo y Construcciones El Hogar Argentino, data de 1889" (Yujnovsky, 1973: 348). Entre las compañías creadas en esos años podemos identificar, además de las citadas en el cuerpo del texto, las siguientes: La Bola de Nieve, Buenos Aires Building Society, La Propiedad, La Habitación, Fomento Urbano (luego continuada por Fomento Urbano y Rural), Banco Inmobiliario Argentino, Sociedad Argentina de Edificación, Sociedad Hipotecaria del Río de la Plata, La Económica, La Edificadora, The Argentine Northern Land Company, Sociedad de Construcciones y Obras Públicas del Río de la Plata, La Inmobiliaria (Lanciotti, 2006).
} 
empresas se formaban con rapidez, pero en muchos casos con la misma velocidad se disolvían en ocasiones envueltas en fraudes denunciados en la prensa.

Aunque las estrategias, modos de asociación e inversión dependieron de la naturaleza y capacidad de los diferentes actores, para alcanzar a los trabajadores fue necesaria la creación de nuevos canales de financiamiento. En efecto, la venta de nuevas tierras y viviendas suponía encontrar compradores. Ello explica la multiplicación de firmas de ahorro y préstamo con el objetivo de captar el pequeño ahorro y transformarlo en créditos para los propios depositantes. Si bien la expansión comenzó a finales del siglo XIX, durante los primeros años del siguiente la coyuntura fue especialmente favorable para este tipo de estrategias en la medida que a la estabilidad monetaria se sumó un mejoramiento de los salarios que permitía a los trabajadores cubrir las cuotas (Cuesta, 2012; Cortés Conde, 1979).

Si bien la historiografía destacó la centralidad de estas firmas en la expansión de los suburbios (Scobie, 1977; Walter, 2016; Yujnovsky, 1974), no identificó que se trataba de compañías que buscaban repicar el modelo de las BS anglosajonas. Esta omisión resulta extraña porque algunas de las sociedades más importantes del mercado, tanto por su volumen como por su perduración, explicitaron su filiación en sus estatutos y publicidades. De hecho, el BHA, que abrió sus puertas 1899, explicitaba en sus memorias que se trataba de una cooperativa de crédito por acciones, "[...] a imagen y semejanza de las instituciones de la misma índole de Europa y Estados Unidos" ${ }^{\prime \prime}$. Su éxito fue inmediato, pues para 1902 contaba con unos 7400 socios y sucursales en Rosario, Córdoba y Bahía Blanca (Ballent, 2014). En 1904 se sumó la Buenos Aires Building Society (BABS) que, a la postre, tendría una gran perdurabilidad en el mercado.

Las declaraciones de objetivos de ambas sociedades, que buscaban articular la búsqueda de ganancias con el mejoramiento de las condiciones habitacionales, tendía a reforzar su vinculación con el movimiento de las BS. Nuevamente, las memorias de EHA no dejaban margen a dudas: "El Banco tiene por objeto estimular el ahorro, facilitar a los socios la adquisición de hogares, y proporcionar seguras e importantes utilidades a las economías de los pobres y a los capitales de los ricos"7. Pero, a la vez, la BABS señalaba:

"[...] no fue un exclusivo propósito de lucro el que nos llevará a construir esta asociación, sino el convencimiento de que hacía falta a nuestra sociabilidad una institución de esta naturaleza para estimular el ahorro sano, constituyendo por su acción cooperativa la gran sociedad de capital aportado en beneficio de la comunidad para devolverlo a la misma en forma de préstamo de edificación entre los asociados, sustrayendo así del juego, del azar y del vicio las pequeñas economías mensuales para destinarlos a la adquisición paciente y paulatina de la CASA PROPIA que al libertar al empleado, al modesto industrial y al obrero de

\footnotetext{
6 BHA, Memoria 1903: 2. A dos años de su fundación esta institución contaba con unos 7400 socios y sucursales en Rosario, Córdoba y Bahía Blanca.

7 Banco el Hogar Argentino, Banco el Hogar Argentino Memoria, 1903: 4.
}

la tiranía del alquiler, contribuye a la formación de hogares independientes en los que como en el HOME INGLÉS, se encuentra la más sólida base de la moralidad de la familia, condición primera de la moral del ciudadano y de la grandeza de las naciones" ${ }^{\prime}$.

La fundación de EHO en 1905 también buscó replicar el modelo de las BS, pero a diferencia de los casos reseñados, implicaba una apuesta más decida por los ideales cooperativos e involucraba a la dirigencia del Partido Socialista. Las primeras publicaciones de institución, de hecho, señalaban que las compras individuales de lotes a plazos no sólo impedían a los obreros abaratar su costo, sino que se agregaba el pago de intereses a los capitalistas (Ronchi, 2016). En este punto, el Partido Socialista no dirigía sus críticas al proceso de "urbanización capitalista" sino a las estrategias de sus agentes, pues entendían que el mercado estaba dominado por especuladores que se aprovechaban de la falta de canales de crédito (Ballent, 2014).

En este plano, las críticas no necesariamente apuntaban a cuestionar la apropiación privada del suelo sino a las prácticas de los actores involucrados. Buena parte de las denuncias realizadas por Juan B. Justo se concentraron en EHA.

“El ejemplar traído por mí de los Estados Unidos, sirvió para fundar El Hogar Argentino, esa institución poderosa que ha acabado por degenerar en una sociedad anónima por acciones, netamente capitalista. Se tomó, para constituir la sociedad, el modelo más capitalista de que se señalan en ese libro [...] Nosotros, en cambio, tomamos el modelo más adelantado, el de la sociedad de Dayton, Ohio, y establecimos una serie de modos de hacer que daba y dan las más positivas ventajas a los socios"

Las críticas de Justo, además de defender su rol como promotor de las BS, buscaban establecer una diferencia clara entre las sociedades que tenían como finalidad ayudar a los obreros de las que sólo buscaban realizar negocios inmobiliarios. Su argumento se entiende mejor al considerar, tal como señala Ballent (2014), que desde finales del siglo XIX los debates distinguían a las cooperativas socialistas de las capitalistas en función no sólo de la propiedad de los medios de producción sino también por los mecanismos de incorporación capital y por el pago o no de intereses. No obstante, los límites entre el sistema utilizado por EHO y EHA eran borrosos y se relacionaban más con la administración de los recursos que con las estrategias para captar capitales y distribuir los beneficios. De hecho, las "ventajas más positivas" a las que refería Justo consistían en que “...no hemos otorgado préstamo de más de 7500 pesos porque hemos entendido que la casa obrera más suntuosa no podría costar en ningún caso más de 7500 pesos incluido el terreno. No préstamos a nadie más de una vez [...] y por otro lado, pedimos que las viviendas fueran destinadas al alojamiento de los socios" (Ronchi, 2016: 57).

\footnotetext{
8 Buenos Aires Building Society, Memoria Sexto Ejercicio, 1910.

${ }^{9}$ Cámara de Diputados de la Nación, Diario de Sesiones, 13 de septiembre de 1915. Citado en Ballent, 2005: 245.
} 
Una diferencia mayor existía en relación al origen de los capitales. Mientras EHO intentaba fondearse con depósitos de los propios interesados y de personas cercanas al movimiento cooperativo, el EHA tenía una marcada apertura al mercado de capitales. Incluso, a partir de 1910 emitió obligaciones no sólo en la plaza local sino también en París. Además, EHA operaba también en la compra venta de inmuebles y contaba con líneas de créditos sin relación con el de ahorro y préstamo (EHA, 1922). Otra divergencia importante fue que EHO construyó viviendas de alquiler lo que permitía sostener la propiedad cooperativa de los inmuebles.

La Primera Guerra Mundial provocó un freno a la expansión del mercado y un cambio en las estrategias de las sociedades analizadas. En 1914 EHA modificó sus estatutos para funcionar definitivamente como un banco hipotecario y sus planes de ahorro y préstamo se transformaron en un sistema de subscripción de títulos amortizables en plazos, denominados como certificados de participación ${ }^{10}$. Desde entonces, y hasta 1922, la institución invirtió m\$n 1.006.144.561 y acumuló unos 3480 créditos para edificación por un valor de $m \$ n$ 35.994.500 (BHA, 1922). Aunque las fuentes son más fragmentarias, al parecer, la BABS también atravesó por transformaciones similares. Finalmente, en 1915 el EHO suspendió los créditos para edificación y se concentró en la sección de consumo que había sido creada en 1911 (Repetto, 1976).

A pesar de estos cambios, el modelo de las BS continuó presente en las discusiones que precedieron a la ley que creó, en 1915, la Comisión Nacional de Casas Baratas (CNCB) ${ }^{11}$. Las mayores presiones para lograr una ley provinieron de sectores de militancia católica, nucleada en torno al proyecto que presentó en 1912 el diputado Juan Cafferata. La propuesta se aprobó tres años después, cuando Ambrosio Nogués, diputado por Tucumán y miembro informante de la comisión parlamentaria, la volvió a impulsar. Entonces, Nogués sostuvo la necesidad de crear BS en Argentina y explicaba su funcionamiento de la siguiente manera:

"Estas sociedades cooperativas, señor presidente, han tenido su principal desenvolvimiento en los Estados Unidos e Inglaterra. En los Estados Unidos las Building Societies proceden a formar su capital en la siguiente forma: se reúne un núcleo de obreros y juntan sus economías en cantidad suficiente para construir una casa, y una vez que está construida, establecen una especie de remate, para adjudicarla a aquel que pueda pagarla en condiciones más ventajosas. Al mismo tiempo se hace una hipoteca sobre la casa construida; lo que permite a las sociedades hacerse de nuevos recursos y poder seguir así seguir sus construcciones"12.

\footnotetext{
10 The Review of River Plate, 30 de septiembre 1910.

11 La creación de esta institución revelaba la preocupación de diferentes sectores de la dirigencia, como por las condiciones habitacionales de los trabajadores. Si bien la huelga de inquilinos tuvo amplia repercusión y el Departamento Nacional de Trabajo presentó un informe sobre las condiciones de vida en los inquilinatos, no resultaron suficientes para instalar dicha problemática en la agenda del gobierno. Suriano (1984).

${ }^{12}$ Cámara de Diputados de la Nación, Diario de Sesiones, 3 de septiembre 1915, en Gutiérrez y Gutman, 1988: 22.
}

La propuesta finalmente no prosperaría y la CNCB se dedicaría a predicar más en el plano teórico que en el empírico :

"Las casas baratas que la comisión construya servirán para cumplir el propósito de higienizar la vivienda popular y fomentar la estabilidad de hogar, dentro de los límites hasta donde puede llegar el Estado con los medios financieros de que dispone al efecto, y también para demostrar prácticamente la posibilidad de que los capitales privados se apliquen con ventaja a la realización de construcciones que, sin dejar de servir a negociaciones beneficiosas para esos capitales, serán obra de bien social" (CNCB, Memorias, 1915: 17).

En rigor, la búsqueda por "dar el ejemplo a la actividad privada" implicaba reconocer la poca influencia del Estado en el mercado, pues en 1915 el 80\% de las hipotecas en vigor correspondían a capitales privados (Pessagno, 1917: 120). Aunque la sanción de la ley puso de manifiesto el interés de algunos sectores por la cuestión habitacional los recursos destinados a la CNCB fueron limitados ${ }^{13}$ y no se produjeron los resultados esperados. No obstante, su creación, así como otras iniciativas públicas especialmente a nivel municipal (Rigotti 2011), revela que el abordaje del Estado tuvo una progresiva transformación (Aguilar 2014). Si bien en líneas generales no se modificó una política que dejaba en manos del mercado la asignación de los recursos, durante la década la década de 1920 los gobiernos desplegaron una intervención más activa. Por ejemplo, los créditos del BHN se concentraron progresivamente en inversiones urbanas. Aunque se trataba fundamentalmente viviendas de alquiler, al punto que la tasación de los inmuebles estaba determinada por su renta potencial, la reforma de la carta orgánica de 1919 amplió la línea dedicada a financiar a los empleados públicos que se remontaba a 1904 (BHN 1986).

Por su parte, también las compañías que logramos identificar, no sólo las señaladas sino otras como El Edificador Rosarino (Cutrúneo 2010), que posteriormente se convertiría en una sociedad de CR, o El Edificador Urbano y Rural, llevaron adelante una estrategia signada por inversiones de bajo riesgo enfocadas en el mercado de alquileres y en la compra venta antes que en los planes de ahorro y préstamo. Pero, al parecer, hacia finales de la década de 1920 el mercado habría de revitalizarse. Entonces surgieron nuevas sociedades, como el Banco de Crédito para Edificación o el Sudamericano de Crédito para Viviendas ${ }^{14}$, entre otras, que aunque no lograron ma-

\footnotetext{
13 Los capitales debían constituirse con lo recaudado por el impuesto a las carreras de los días jueves, a lo que se sumarían los fondos que debía establecer el Congreso Nacional en cada presupuesto, y los préstamos de la Caja de Ahorro Postal Primer Congreso Argentino de la Habitación, en Boletín del Museo Social Argentino, Buenos Aires, Tomo IX, 1920: 106. Además de resultar ínfimas las sumas obtenidas mediante el gravamen mencionado, los recursos presupuestarios no fueron asignados, mientras que los préstamos de la Caja de Ahorro no fueron habilitados. En relación con éste último, el Congreso había establecido tasas del 3\%, las que se contraponían con la ley de esa Caja que las fijaba en el $5 \%$ con lo cual quedaba invalidad su utilización. Diario La Nación, 14 de mayo de 1920. Dr. Carlos M. Coll, presidente de la Comisión de Casas Baratas

14 Las referencias de estas empresas fueron extraídas de las notas de la Revista Sudamericana y La Información entre 1938 y 1949. No hemos logrado encontrar otros registros.
} 
yor perduración constituyeron un antecedente más directo de las compañías de CR. En ese escenario, la BABS, modificó sus planes y fue incluida por la IGJ dentro de las normativas que alcanzaban a dichas sociedades (lóvine, 1947). Por su parte, el EHA en 1941 el BHA creó una compañía de CR denominada CIFRA, cuyo paquete accionario controlaba ${ }^{15}$.

Finalmente, el impacto de la crisis de 1929, con la consiguiente retracción de las actividades agropecuarias y crecimiento de las industriales, transformó al mercado debido al aumento de las tasas de urbanización. Sin embargo, dicho crecimiento no se tradujo en una ampliación inmediata ni de la cantidad de créditos ni de las compras o construcciones de viviendas. En efecto, el impacto de la crisis no sólo fue intenso sino también prolongado. De hecho, los depósitos conjuntos de ahorros en el país se contrajeron hasta 1933, escenario en el cual el BHN, por ejemplo, lanzó una conversión de sus cédulas con el objetivo proteger su cartera del aumento de la mora y frenar la caída del precio de las propiedades (BHN, 1986).

Otros indicadores asociados más directamente al segmento de viviendas, como los permisos de construcción y la compra venta de inmuebles en ciudades como Buenos Aires (Yujnovsky, 1984; Clivchesky, 1973) y Rosario (Lanciotti et al, 2020) y la cantidad de hipotecas firmadas en el país, indican que la reactivación del mercado comenzó hacia mediados de la década (Gómez y Gilbert, 2019). En ese escenario, se multiplicaron las firmas que aplicaban diversos planes de ahorro y préstamo entre las que se destacaron las sociedades de CR porque tuvieron el mayor crecimiento.

En ese sentido, el surgimiento de las sociedades de $C R$, se dio en un contexto de cierta renovación del mercado impulsada por una demanda en expansión. Pero desde una perspectiva de más largo plazo es posible afirmar que mientras la multiplicación de compañías enfocadas en viviendas derivaba de las nuevas posibilidades que ofrecía el mercado, la apuesta por los modelos de ahorro y préstamo, y en especial en el caso del CR, respondía al resurgimiento de una experiencia acumulada por el mercado local que habría de resurgir cuando las condiciones lo permitieron.

\section{El Crédito Recíproco}

Las compañías de $\mathrm{CR}^{16}$ aplicaron a partir de 1935 un modelo de ahorro y préstamo, que no computaba intereses a los ahorros ni los cobraba a los créditos, inspirado en el modelo de las CAE alemanas. La modalidad se identificó con diferentes

\footnotetext{
15 El capital originario de CIFRA fue compuesto de la siguiente manera: $\$ 2.000 .000$ divido en acciones de $\$ 1.000$, repartidas en 4 series iguales. Suscripción de acciones: Banco El Hogar Argentino hipotecario, 590; Octavio S Pico, Agustín Melián, Ernesto Ferrari, Emilio F Cárdenas, Cornelio Vivanco, Luis Mitre, José A González, M.A Portela Ramírez, Eduardo Rocha, Juan M O'Farrel, 1 cada uno. Su directorio estaba compuesto por Emilio F Cárdenas, Cornelio Vivanco, Octavio S Pico, Agustín Melián, Ernesto Ferrari, Luis Mitre, José A González, Manuel Portela Ramírez y Eduardo Rocha; Síndicos Juan M O'Farrel y Darío Hermida. IGJ, Boletín Mensual, Marzo, 1942.

${ }^{16}$ Ver Cuadro 1.
}

nombres, entre ellos el de CR era el más usual, aunque la IGJ tendía a utilizar el de Sociedades de Ahorro para la Vivienda. Para comienzos de la década de 1940, pocos años después de su aparición, se habían convertido en uno de los principales actores del mercado y funcionaban, a la vez, como sociedades financieras y como empresas de loteo y construcción (Gómez, 2014).

En términos prácticos, el mecanismo de financiamiento que estas sociedades aplicaban consistía en la creación de círculos de ahorro destinados a la formación de capital para préstamos hipotecarios que se entregaban a los adherentes cuando acumulaban el equivalente al $20 \%$ del valor del inmueble que se proyectaba comprar o construir, aunque también se incluían otros mecanismos como los sorteos y las licitaciones ${ }^{17}$. Una vez ahorrado un porcentaje predeterminado del valor a través de cuotas periódicas la sociedad entregaba un préstamo garantizado en hipotecas que cubría el $80 \%$ restante (Martín, 1943).

Como se ha señalado, los fondos para financiar los créditos se reunían a través de los depósitos regulares de los socios de manera que la capacidad del sistema descansaba en el "ahorro colectivo". Por su parte, si bien existían acuerdos sin intereses regularmente los contratos no los eliminaban, sino que cobraban la misma tasa a los préstamos que la que cargaban a los depósitos. De allí su "neutralización" e identificación como "recíprocos" (lóvine, 1947).

Como se ha señalado anteriormente, las sociedades de $C R$ ingresaron en un mercado en que los créditos hipotecarios eran reducidos y regularmente cubrían hasta el 50\% del capital (Gómez, 2013). Hacia mediados de la década del treinta esas condiciones se combinaron con un aumento de la concentración demográfica que agudizó aún más el déficit de viviendas, con cierta recuperación de los niveles actividad y los salarios y con un escenario empresarial en que diversos actores buscaban nuevas oportunidades de negocios dado el estancamiento de las actividades tradicionales.

Si bien el incentivo inmediato de la elección del CR fue el aumento de la demanda de viviendas y de trabajadores en condiciones de destinar una parte de sus ingresos al ahorro, también fueron importantes las experiencias previas acumuladas en el área. De hecho, algunos directivos y accionistas de las empresas de CR eran miembros de otras compañías con una larga trayectoria en el mercado como en el caso de C.I.F.R.A y EHA. También, al igual que los casos analizados de comienzos de siglo, la influencia de la experiencia internacional de las BS anglosajonas y de las Cajas de Ahorro para Edificar alemanas

\footnotetext{
${ }^{17}$ Ver Armando Felici, Revista Veritas, 1940, “El crédito Recíproco". La publicidad de las empresas en este sentido, también era muy específica. Todas las empresas de CR estaban obligadas a editar una publicación con la evolución de las cuentas destinadas a sus socios. Algunas de ellas, como A.R.C.A. S.A y F.I.N.C.A convirtieron a la publicación en un vehículo de publicidad organizando revistas que combinaban una sección de arquitectura con otra destinada al CR y la evolución de las empresas. De esas publicaciones se puede extraer información sobre la organización de los planes de ahorro y estrategias de las empresas. Sobre la relación entre depósitos y crédito ver Arca, Revista para el Hogar, "El Crédito Recíproco es la piedra fundamental para la casa propia", Diciembre 1936. Otras publicaciones especializadas, como la referida Veritas, Sudamericana, Temas Económicos, La Información, Balances, entre otras, se ocuparon pormenorizadamente de las características y evolución del sector.
} 
durante el período de entreguerras fue muy importante, al igual que en otros países de la región ${ }^{18}$. Sobre esta influencia indicaba Jorge Estrogamou, presidente de C.O.F.R.E:

"La solución para dotar a la población de vivienda propia, ha pretendido ser buscadas por diversos procedimientos financieros, a saber: creación de Comisiones de Casas Baratas, Asociaciones privadas que bajo la forma de cooperativas faciliten dinero para su construcción [...], pero todos esos sistemas fracasan [...] Una nueva actividad financiera en nuestro país, trae consigo la solución de este importante problema; esta actividad es la denominada Crédito Recíproco, que ya en Europa y Estados Unidos ha producido óptimos resultado"19.

En una línea similar, algunas de las publicaciones económicas más importantes del país, como Veritas o Sudamericana, que a la postre se ocupó sistemáticamente del $C R$, depositaban en la experiencia internacional buena parte de sus esperanzas. Al respecto, las editoriales de la revista Sudamericana sostenían:

"Hace ya algún tiempo se han incorporado a la labor nacional las sociedades de crédito recíproco, sistema que se desconocía entre nosotros, pero que se estaba utilizando con gran éxito en Alemania, Inglaterra y Estados Unidos, para propender a facilitar la adquisición de la vivienda propia. Realizan esta clase de empresas cuando son administradas con corrección una obra verdaderamente valiosa"20

El CR fue gestionado por sociedades anónimas e impulsado inicialmente por empresarios alemanes entre los que se destacaban Udo Meckeler, gerente de A.R.C.A S.A y Erich Zeyen presidente de F.I.N.C.A. S.A. Dichas firmas fueron las primeras en funcionar en el país. Estas empresas, al igual que en Brasil (Gómez y Correa, 2013) y también en Uruguay, dónde se fundó una compañía denominada O.C.R.I.S.A ${ }^{21}$ a principios de los cuarenta, no eran sólo entidades financieras, sino que también tenían vínculos con el mercado inmobiliario y la construcción. En ese sentido, la organización sistema puede ser entendido como un medio para generar capitales a costos muy bajos en un contexto en que el mercado de crédito privilegiaba otros segmentos.

Si bien es complejo identificar registros de todas las sociedades, pues en numerosos casos sólo aparecen datos fragmentarios, muchas veces a partir de publicidades e informes

\footnotetext{
18 De hecho, esta modalidad de ahorro y préstamo ingresaría primero en Brasil, bajo el nombre de Sociedades de Economía Colectiva o Cajas Constructoras, y luego se difundió hacia la mayoría del continente. El Estado brasileño reglamentó el funcionamiento de las Cajas Constructoras a partir de 1934, y para el siguiente año las estadísticas mencionaban 19 sociedades, de las cuales, según los mismos datos, sólo cuatro funcionaban con pautas similares a las sociedades anglosajonas. Regularmente, tenían una organización cooperativa y muchos miembros de los directorios participaban simultáneamente de empresas constructoras (Gómez y Correa, 2013).

19 Revista Balances, "El Problema de la Vivienda Propia y las Perspectivas del Crédito Recíproco en la República Argentina", enero, 1942.

20 Revista Sudamericana, "Deben ser reglamentadas las sociedades de Crédito Recíproco", octubre, 1937

21 Revista Sudamericana, “OCRISA y la ley de Crédito Recíproco”, Febrero, 1943
}

publicados en la prensa, en otros se trató de firmas de vida efímera o inclusive que no realizaron las correspondientes inscripciones legales, logramos evidenciar que hacia 1943 existían formalmente quince empresas mientras que en 1949 se habían reducido a trece. Sin embargo, el impacto del sector no debe medirse exclusivamente en razón de su evolución cuantitativa, sino también en función de su capacidad para construir viviendas. En efecto, algunas compañías del sector lograron materializar emprendimientos de gran envergadura. Por ejemplo, F.I.N.C.A construyó un barrio en la localidad de Beccar, en la zona norte del conurbano bonaerense, y otro en El Palomar, en zona oeste, que contaba para 1955 con unas 3400 viviendas siendo una de las mayores urbanizaciones del período. Otras firmas como A.R.C.A, también contaron con gran capacidad, pues sin contar los préstamos individuales, que algunas fuentes registran en unos 9000 (Martín, 1966) las memorias de la empresa contabilizan unas 800 viviendas bajo su gestión directa hacia 1949 .

Según los promotores del CR, el déficit de viviendas era el resultado de las orientaciones del mercado de capitales, que no realizaba inversiones de largo plazo y bajos intereses ${ }^{22}$. Ello se traducía en un déficit crónico que, por otra parte, generaba condiciones favorables para las inversiones en edificaciones de renta lo que tendía a realimentar el ciclo. De esta manera, el problema era esencialmente crediticio y su solución descansaba en reunir capitales que, debido a su naturaleza, permitieran corregir los mecanismos de asignación. En esa línea, según indicaba la publicidad de las compañías, la propuesta era simple y consistía en combinar el pequeño ahorro con una eficiente administración empresarial para lograr adquirir una vivienda sin pagar créditos usurarios ni cuotas que superaran el valor del alquiler promedio.

Las diferencias se establecieron en torno a la conveniencia de eliminar o introducir el cobro de intereses y fueron resultado, sobre todo, de los debates que provocó la regulación del sistema por parte de la IGJ. Básicamente las posturas se identificaron con las experiencias o anglosajonas o alemana. Así, la literatura sobre el CR esencialmente consistió en una casuística de dichos casos, a modo de descripción de los orígenes, y las posiciones se expresaron en la promoción de uno de los dos "modelos"23. También las empresas concentraron sus intentos

\footnotetext{
22 En su primer número la revista de la compañía A.R.C.A sostenía que “Las posibilidades existentes en la República Argentina para la obtención de préstamos destinados a la adquisición de la casa propia son muy limitadas. En los pocos casos en que se puede conseguir el dinero necesario por medio de hipotecas comunes, el deudor queda obligado por condiciones tan desventajosas y debe abonar intereses tan elevados que la operación le significa cargarse de deudas por el resto de su vida". Revista Arca para el Hogar, "El crédito reciproco es la piedra fundamental para la construcción de la casa propia". Diciembre, 1936

23 En la literatura publicada en Argentina mayoritariamente se promueve modalidad con intereses con la excepción de los trabajos de J Martín, quién en su primera publicación de 1943, cuando era gerente de ARCA, defendía el crédito sin intereses. No obstante, en 1966 defendería la reinserción de la modalidad con intereses y la creación de un marco institucional similar al norteamericano. Para entonces Martín se desempeñaba como asesor de sociedades de ahorro y préstamo para la vivienda en Brasil y Venezuela. También, dentro de la Agencia Internacional de Desarrollo, participaba de cursos y seminarios destinados a analizar el problema de la vivienda y a promover el ahorro y préstamo en América Latina. En ese contexto fue uno de los principales promotores de la reinserción de la modalidad durante la década de 1960 Adolfo Lamas, quien también se desempeñaría como técnico, en Centroamérica promovería el cobro de intereses.
} 
por legitimar sus operaciones en la selección de la experiencia más acorde a los planes que utilizaban. Por ejemplo, F.I.N.C.A utilizaba el de CAE mientras otras firmas importantes, como CIFRA, COFRE (y posteriormente también A.R.C.A) utilizaban el de BS o Sociedades de Ahorro para la Vivienda, que era el indicado por la IGJ (lóvine, 1947).

Por otra parte, regularmente los miembros de los directorios de las empresas de CR tenían intereses en compañías financieras, especialmente en los sectores de capitalización, seguros y bancos, y también en firmas constructoras e inmobiliarias. De hecho, en la fundación de A.R.CA. ${ }^{24}$ tuvo una participación central el estudio de arquitectura Sánchez, Lagos y De la Torre, uno de los más importantes del país, mientras que F.I.N.CA. ${ }^{25}$ fue organizada por una compañía inmobiliaria. En rigor, inicialmente las compañías de CR no se dedicaban de forma exclusiva a la intermediación crediticia, sino que sus actividades incluían loteos, construcción y venta de viviendas lo que refuerza la idea de que la aplicación del sistema buscaba crear canales de financiamiento para movilizar las actividades conexas de los empresarios involucrados. Por ello los estatutos de las firmas contenían objetivos muy amplios. A modo de ejemplo, en el caso de ARCA, el primer artículo del reglamento aprobado por la IGJ en 1938 indicaba que "La sociedad concede préstamos hipotecarios para adquisición, edificación, reparación o ampliación de la casa propia, comprendiendo el valor del terreno o sin él, acuerda asimismo hipotecas so-

\footnotetext{
${ }^{24}$ La Asociación Argentina de Crédito Recíproco S.A. (A.R.C.A.S.A.) fue creada en julio de 1935 como sociedad de préstamos hipotecarios para adquisición, edificación reparación o ampliación de la casa propia. Podía otorgar hipotecas sobre inmuebles urbanos o rurales y otorgar préstamos, libres de interés, hasta un monto de treinta mil pesos. La iniciativa fue de uno de los estudios de arquitectura más importantes de Buenos Aires que fue fundado, en la década de 1920, por el ingeniero Gregorio Sánchez y los arquitectos Gregorio Lagos y Luis M. de la Torre. Capital: $\$ 500.000 \mathrm{di}$ vidido en 5 series de $\$ 100.000$ y en acciones de $\$ 100$ cada acción. Este capital podrá elevarse hasta $\$ 5.000 .000$. Distribución de utilidades: $5 \%$ reserva legal, $15 \%$ al direc torio y del resto dispone la asamblea. Suscripción de acciones: Luis M de la Torre, 100 Dr. Alberto Julián Martínez, 100; Dr. Pablo Cárdenas (h), 100; Dr. Jorge B Ramallo, 100 Ing. Gregorio L. Sánchez, 100; Arq. Ernesto Lagos, 100; Enrique Pujadas, 100; Mauricio B Presser, 100 acciones. Fuente: La Información. Revista Mensual. Para un análisis más detallado sobre la composición de la empresa ver Gómez y Gilbert (2015).

25 La firma fue organizada en 1935 por los empresarios alemanes Germán Wernicke y Erich Zeyen y contó con lazos con otros empresarios de la comunidad como Gustavo Herten, Fhurmann S.A, sociedad que financió la compra de los terrenos F.I.N.C.A tenía además relaciones con personalidades ubicadas en importantes posiciones en el gobierno durante el peronismo, como el Vicepresidente de la Nación Alberto Tessaire, amigo personal de Zeyen, el Diputado y presidente de la cámara baja Alberto J. Benítez, abogado de la firma, y Enrique Plate, quien ocupó distintos cargos públicos y fue miembro del directorio de la empresa. El capital autorizado fue de $m \$ n 250.000$ dividido en 500 acciones de 100 pesos cada una, representado por 5 series. El capita suscripto fue de $m \$ n 50.000$ y el realizado de $m \$ n$ 5.000. Las acciones fueron subscriptas por German Wernicke, 100; Erich Zeyen 252; Juan Beherent y Hugo Zeyen 44 acciones cada uno; Herald Maurer, Luis Badino, Oreste Sabatini, Gertrud Wagner Hans Wagner y Ricardo Muller, 10 acciones cada uno ". Su primer directorio fue compuesto por German Wernicke y Eric Zeyen, como directores y Hugo Zeyen, hermano de Eric, y Luis Badino como síndicos. Monitor de sociedades anónimas, Febrero, 1935. Para un análisis más detallado sobre la composición de la empresa ver Gómez y Gilbert (2015). Germán Wernicke, que se convirtió en el primer presidente de la empresa, era una persona con sólidos vínculos dentro de la comunidad empresarial alemana en Argentina. Era directivo de las siguientes empresas Robert Bosch S.A y Anilinas Alemanas S.A, Acero RoechlingBuderusS.A, Perfumerías Tosca S.A, La Rura Seguros, La Rural Buenos Aires, Lita S.A Explotación Ganadera y Agrícola, La Protectora Seguros, Gerente de M. Hohner y Cía. Sociedad de Responsabilidad Limitada. Revista Finca, marzo de 1940, "Seguridades que ofrece Finca a sus adherentes por las entregas de ahorro". No hemos logrado encontrar datos sobre la biografía de Zeyen, aunque pudimos identificar que su trayectoria como empresario en Argentina estuvo reducida exclusivamente a F.I.N.C.A..
}

bre bienes inmuebles, ya sean urbanos o rurales, sustitución de las mismas y para toda clase de operaciones hipotecarias" (Martín, 1943: 194). En la misma línea, los objetivos autorizados a S.U.C.A en febrero de 1937 la habilitaban para operar con "Préstamos con garantía hipotecaria, construcción de casas para uso propio o de terceros o para rentas, y adquirirlas y venderlas" ${ }^{\prime 26}$.

Como se ha señalado, las tendencias del mercado dejaban un margen abierto para explotar un segmento, el de ahorro y préstamo enfocado en los trabajadores con ingresos regulares, que contaba una larga tradición en el país. En ese escenario, la organización del CR ofrecía a los empresarios ingresar al mercado sin grandes inversiones, pues los capitales se generaban con los aportes de los socios, y prometía importantes beneficios en función del volumen potencial de clientes. En este punto, lo relativamente novedoso del CR era el intento por crear nuevos recursos y sobre todo apostar por un criterio de asignación de los préstamos que no se apoyaba en los ingresos de los tomadores sino en la regularidad de sus pagos y en cubrir el $100 \%$ del valor de las propiedades ${ }^{27}$.

La búsqueda de lograr utilidades no obtura, sin embargo, otros objetivos en la vida de las empresas (Coriat y Weinstein, 2011). En el caso del CR, aunque las trayectorias distaron de ser homogéneas y la dinámica sectorial estuvo atravesada por denuncias de manejos poco transparentes, existieron compañías que vincularon su actividad con objetivos sociales y desarrollaron proyectos que sugieren cierto compromiso con estas ideas. Pero, además, el sector buscó relacionar su funcionamiento con el fomento del ahorro y el acceso a la propiedad, a los que se les atribuía una dimensión pedagógica y moralizante. Esos planteos, en términos más generales, se entroncaban con la promoción de prácticas colaborativas ligadas al mutualismo y el cooperativismo, así como con las nociones ligadas a las ideas de reciprocidad y comunidad, que los representantes de las firmas nunca dejaron de destacar.

Inicialmente, estos discursos se vinculaban con la eliminación de los intereses. Así, la revista FINCA sostenía: "No somos magos. No podemos decir abracadabra y levantar el lienzo y entregar la casa lista y paga, pero si podemos [...] porque que la unión hace la fuerza, prestar dinero sin interés"28. En la misma línea, el número inaugural de la Revista Arca para el Hogar, de la empresa homónima, a finales de 1936 se preguntaba "Para qué pagar interés, por un dinero que en realidad pertenece a un grupo de personas de personas con intereses coincidentes y recíprocos que también quieren ser propietarios de su casa propia. El sistema de economía colectiva, reúne esos intereses comunes, y permite disponer del importe necesario"29.

Hacia el final de la editorial se destacaba también el ahorro común o colectivo. Pero estas posiciones no eran defendidas sólo por los empresarios. En 1942 la revista Balances dedicó una serie de números al estudio del CR donde se sostenía que:

\footnotetext{
26 Revista La Información, Febrero, 1937: 17

27 Para un análisis sobre las características del crédito hipotecario entre 1930 y 1945 ver Gómez y Gilbert, 2019.

28 Revista Finca, marzo 1938, “Como se llega a la casa propia?”.

29 Revista Arca, diciembre 1936, “El camino a seguir”.
} 
"Expresamente hemos dicho colectivo porque la formación de capitales que facilitan las compañías de crédito recíproco para la edificación o compra de la casa propia, se basa en la colectivización del ahorro y esta fue la idea inicial de sus creados en el mundo, entendiendo que una comunidad podía en menor tiempo reunir el dinero para que cada uno de sus integrantes llegase a satisfacer la aspiración, al par que la necesidad, de habitar mejor [...]El ahorro individual, estático, que no persigue un fin determinado, sino que responde a sensación de avaricia es tan grave en sus consecuencias económicas, morales y sociales como el vilipendio; pero, cierto es también que quien no ahorra vive siempre al borde de las privaciones y camina hacia la miseria. El ahorro colectivo, con mira a la satisfacción de una necesidad, alcanza a producir el goce esperado" ${ }^{30}$.

En rigor, la búsqueda por generar ahorros comunes tenía que ver con la necesidad de obtener nuevos capitales dado que los empresarios vinculados al sector entendían que el problema habitacional era esencialmente financiero. Al respecto, Eduardo Perotti, periodista que dedicó dos libros al sector, señalaba que "La atención total de los poderes públicos y de los estudiosos de este problema debe enfocarse con toda decisión hacia la búsqueda de soluciones de carácter exclusivamente financiero" (Perotti, 1943: 26). En esa línea, el aporte del CR consistía en crear nuevos capitales provistos por ahorristas motivados por una futura de una vivienda, pues de otra manera no tendrían relación con las instituciones financieras. En ese sentido, Adolfo Lamas sostenía que "Podría asegurarse que un porcentaje no inferior al $90 \%$ de sus ahorradores, son personas que ahorran exclusivamente movidas por el incentivo de la casa propia y que no podrían ser clientes de otros sistemas de ahorro porque son individuos de poca capacidad económica para lo que un ahorro ordenado y sistemático representa siempre un sacrificio" (Lamas, 1950: 61). Vale destacar que este argumento era defendido también lóvine (1947) y Pardo (1947), cuadros técnicos de la IGJ y encargados de regular al sector, así como por Raúl Fitte (1942) que funcionario del BHN, lo que tiende a sugerir en buena medida los apoyos que el sector recibió estaban motivados por esta mirada.

En esa línea, la hipótesis, relativamente consensuada por los libros y tesis enfocadas en el CR, sostenía que el déficit habitacional era un problema financiero y que las fallas del mercado de crédito radicaban más en el limitado porcentaje que los préstamos cubrían respecto de la valuación de las propiedades que en el costo del dinero (Perotti, 1944: 39) ${ }^{31}$. Sin embargo, dichos estudios no analizaron las tendencias del mercado y para apoyar sus posiciones se enfocaban en las políticas de las instituciones oficiales y fundamentalmente del BHN. En este punto, Armando Felici, quién publicó varios artículos en diferentes revistas económicas como Veritas y Sudamérica y también en publicaciones de las empresas $C R$, sostenía que por fuera de dicho sistema "...las posibilidades de obtener

\footnotetext{
30 Revista Balances, julio 1942, "Crédito Recíproco. Una casa para cada familia”.

31 En este punto es importante señalar que el análisis del CHN indica que el interés promedio del mercado no era excesivamente caro, aunque el alto grado de informalidad de las operaciones dificulta realizar conclusiones muy contundentes.
}

créditos [...] son (además de muy reducidas) muy onerosas y (para la clase media de los trabajadores, empleados, pequeños comerciantes, etc.) prácticamente inexistentes" ${ }^{\prime \prime 2}$.

En efecto, tanto el BHN como el mercado privado, tendieron a sostener una estrategia conservadora que implicaba financiar hasta el 50\% del valor de las propiedades lo que hacía necesario contar con importantes capitales propios para poder materializar las operaciones. Ello implicaba que el crédito se concentraba en quienes ya contaban con capitales propios lo que reforzaba la segmentación. Al respecto, Felici sostenía "Los capitalistas entre tanto no han perdido el tiempo [...] y han encontrado un modo muy lucrativo y seguro, invirtiendo sus recursos en casas de departamentos, por los que cobran alquileres generalmente exorbitantes, mientras los trabajadores, empleados, etc. se encuentran desarmados frente a sus pretensiones por la imposibilidad de independizarse y por el desamparo absoluto en que los deja la ley"33. En esa línea, se insistía también en que quienes no podían acceder al mercado formal dependían del crédito ofrecido por los rematadores que eran denunciados con frecuencia por prácticas abusivas. En este punto, también existían tensiones. Mientras analistas como Fitte, Perotti y Martín, quien escribió su primer libro sobre el CR por pedido de Julián Martínez, presidente del BHN, Enrique Peréz, quién fuera reemplazado por este último, atribuía el éxito de las sociedades de ahorro y préstamo no a sus características sino a prácticas fraudulentas.

De esta manera, al menos discursivamente, la organización del CR involucraba una apuesta muy ambiciosa, pues pretendía corregir los mecanismos de asignación del crédito. En ese punto, el planteo consistía en segmentar el mercado entre quienes no poseían recursos y debían financiamiento público, los sectores medios que debían ser financiados por las sociedades de ahorro y préstamo y, por último, quienes podían ser alcanzados por las instituciones hipotecarias tradicionales (Lamas, 1950; Rottin, 1950).

Por otra parte, además, en las publicidades de las diferentes firmas, y puntualmente en las revistas de ARCA y FINCA, abundaban las editoriales que proponían como solución al problema habitacional y como un medio para de reformar las condiciones de vida de los trabajadores el entorno suburbano y el modelo de las ciudades jardín. Si bien el desplazamiento hacia los suburbios respondía a los costos relativos de los terrenos, interesa observar también que algunas de las urbanizaciones desarrolladas por estas firmas permiten identificar que de dichas ideas tuvieron algún nivel de materialización (Harispuru y Domínguez, 2009).

En ese sentido, así como resulta difícil separar el movimiento internacional de las BS y el avance de los suburbios con predominio de los barrios jardín en los casos europeos y norteamericano, en el caso argentino, las empresas de CR también fueron protagonistas de la difusión del modelo de las ciudades jardín (Dines, 2016). En la etapa bajo estudio, y fundamentalmente para las empresas bajo análisis, dicho proyecto urbanístico implicaba una crítica a los efectos sociales, higiénicos y

\footnotetext{
32 Armando Felici, El Crédito Recíproco, Revista Finca, enero 1941.

33 Armando Felici, Revista Veritas 15 de noviembre de 1940, El Crédito Recíproco.
} 
morales, que se le atribuía al desordenado crecimiento urbano. Por esta vía, frente a un pasado valorado como decadente, y asociado al conventillo, el hacinamiento y la especulación inmobiliaria, las empresas de CR prometían un futuro de propietarios de casas con jardín en un entorno pacífico y resultado de los ahorros compartidos.

Conclusiones

El estudio del CR estuvo ausente en la agenda de los investigadores que analizaron el problema habitacional en $\mathrm{Ar}$ gentina. Dicha omisión implica un importante vacío historiográfico por diferentes motivos. En primer lugar, debido a su importante participación en el mercado de crédito su estudio resulta central para comprender la evolución tanto del sector financiero como de la industria de la construcción durante el período clásico de industrialización sustitutiva. Por otro lado, su análisis contribuye a problematizar las estrategias de los empresarios y de los asalariados relacionadas con el mercado de viviendas. En esa línea, además, las compañías de CR constituyen un caso de interés para analizar los mecanismos de generación de ahorros de parte de los sectores trabajadores, así como los cruces entre los intereses económicos y sociales de los empresarios involucrados. Por último, aunque no ha sido objeto de este artículo, también resulta un caso paradigmático para estudiar las condiciones del mercado de crédito para cubrir la demanda de viviendas antes y durante la aplicación de los planes de vivienda masivos del primer peronismo.

En este punto, concluimos que falta de estudios sobre el CR responde no sólo a su identificación como simples empresas hipotecarias sino al interés por discutir las políticas de vivienda del peronismo, lo que no sólo contribuyó a desdibujar la etapa previa sino a concentrar los análisis en el rol de las instituciones públicas. Aquí nuestro argumento reconoce que las políticas habitacionales del peronismo significaron una transformación fundamental para la historia del crédito en Argentina. Sin embargo, sostiene también que, si se coloca la mirada en las continuidades con el período previo y se analiza la proliferación de compañías de ahorro y préstamo, como el CR, su relación con los modelos internacionales y su fuerte gravitación en el mercado se puede construir una imagen más matizada que la que se centra exclusivamente en la actividad del Estado. Pero, además, permite refutar la noción que sostiene que hasta la llegada de los planes de vivienda del peronismo prácticamente no existían instituciones de crédito enfocadas en la vivienda obrera.

En esa línea, una mirada de largo plazo permite identificar la fuerte influencia de las BS sobre el mercado local. Dicha ascendencia motivó su temprana a comienzos del siglo XX. La dinámica del ciclo económico marcó los límites de la expansión del mercado de crédito a mediados de la segunda década del siglo XX y colocó un freno a la expansión del sector. Sin embargo, cuando las condiciones lo permitieron, a partir de la reorientación económica de los treinta, resurgieron las experiencias de ahorro y préstamo, bajo la forma del CR, esta vez estimuladas también por las experiencias europeas. En este sentido, si bien las diferencias conceptuales son difusas temporalmente son más nítidas. Así, a comienzos de siglo las sociedades locales buscaron copiar el modelo ahorro y préstamo basado en el cobro de intereses, mientras en los treinta emularon el que los eliminaba y reintrodujeron los planes contractuales.

Los problemas vinculados a la construcción del marco institucional específico para las sociedades de CR serán objeto de futuros trabajos. En una agenda de investigación de más largo plazo, este artículo evidencia la relación entre las sociedades de $C R$, con la historia del mercado local, con la influencia de los casos internacionales y con su apelación a valores solidarios y mutualistas. La pesquisa evidenció no sólo que la vinculación entre BS y CR permitió lograr condiciones especiales para el sector en Argentina y que los empresarios locales, si bien tenían como objetivo generar negocios financieros e inmobiliarios, buscaron también cumplir objetivos sociales. En esa línea, el ahorro compartido y la eliminación de los intereses fueron no sólo una apelación de carácter publicitario, sino que también orientaron las estrategias de las empresas más importantes del sector. 
Bibliografía

ABOY, R. (2005): Viviendas para el pueblo. Espacio urbano y sociabilidad en el barrio Los Perales, 1946-1955, Buenos Aires, Fondo de cultura Económica.

AGUILAR, P. (2014): El Hogar como problema y como solución. Buenos Aires, Ediciones del Centro Cultural de la Cooperación Floreal Gorini.

ARMUS, D. y HARDOY, J. (1990): “Coventillos, ranchos y casa propia en el mundo urbano del novecientos". ARMUS: Mundo Urbano y Cultura Popular. Estudios de Historia Social Argentina, Buenos Aires, Sudamericana.

BALLENT, A. (2005): Las huellas de la política. Buenos Aires, Universidad Nacional de Quilmes- Prometeo.

BALLENT, A. y LIERNUR, F. (2014): La casa y la multitud. Vivienda, política y cultura en la Argentina moderna. Buenos Aires, Fondo de Cultura Económica.

BANCO HIPOTECARIO NACIONAL (1961): 75 Aniversario (1886-1961), Buenos Aires, Banco Hipotecario Nacional.

BANCO HIPOTECARIO NACIONAL (1986): Balance de un siglo (1886-1986), Buenos Aires, Banco Hipotecario Nacional.

BELLMAN, H. (1927): The Building Society Movement, Londres, Methuen $\&$ Co.

BENES, B. (1966): Las Asociaciones de ahorro y préstamo, Washington, WFLA.

BLAT, J. (2000): Vivienda obrera y crecimiento urbano (Valencia 18531936), Valencia, Generalitat Valenciana.

BODFISH, M. (1931): History of Building and Loan in the United States, Chicago, United States Building and Loan League.

BODFISH, M. y THEOBALD, A. (1940): Savings and Loan Principles, Nueva York.

BOLEAT, M (1981): Building Societies. A descriptive study. https://books. google.co.uk/books?id=dLwaUqfrDgYC\&printsec=frontcover\&dq=b uilding+societies+a+descriptive \&hl=en $\&$ sa $=X \& e i=1 \mathrm{gFOUei} 4 \mathrm{EoHOO}$ QX3joHYCA\&redir_esc $=y \# v=$ onepage $\& q=$ building $\% 20$ societies $\% 20$ a\%20descriptive\&f=false.

BUNGE, A. (1940): Una Nueva Argentina, Buenos Aires, Hyspamerica,

CALCAGNO, M. (1958): El problema de la vivienda: problema crediticio, Buenos Aires, Universidad de Buenos Aires.

CAMERON, R. (1974): La banca en las primeras etapas de industrialización, Tecnos, Madrid.

CAPEL, H. (2013): La morfología de las ciudades. Agentes urbanos y mercado inmobiliario. Barcelona, Ediciones del Serbal.

CLICHEVSKY, N. (1973): El mercado de tierras en el área de expansión de Buenos Aires y su incidencia sobre los sectores populares, 1943-1973, Buenos Aires, CEUR.

CORIAT, B. y WEINSTEIN, O. (2011): Nuevas Teorías de la Empresa. Una revisión crítica, Buenos Aires, Lenguaje Claro.

CORTES CONDE, R. (1979): El progreso argentino, 1880-1914. Buenos Aires, Editorial Sudamericana.

CORTÉS CONDE, R. (2011): La Cédula Hipotecaria Argentina, el Banco Hipotecario Nacional (1886-1946), Buenos Aires, Banco Hipotecario Nacional.

CORTES CONDE, R. (2005): La economía política de la Argentina en el siglo $X X$, Buenos Aires, Edhasa,.

CUESTA, M. (2012): "Precios y Salarios en Buenos Aires durante la Gran Expansión, 1880-1914", Revista de Instituciones, Ideas y Mercados, 56, pp. 159-179.

CUTRUNEO, J. (2010): “Entidades de vivienda. El caso del Banco El Edificador Rosarino (Rosario, 1924-1929), Revista de Historia Americana del Instituto de Geografía, 143, pp. 5-21.
DINES, M. (2016): Garden Cities of the Americas: Greenbelt and EI Palomar, a Comparative Case Study on the Model's Translation to the American Continents. Univerisidad de Miami Open Access Theses, Miami.

ENGELS, F. (1986): El problema de la vivienda, Buenos Aires: Editorial Anteo.

FITTE, R. (1942): Fomento de los préstamos para edificación y en especial para la vivienda económica, Buenos Aires, Banco Hipotecario Nacional.

GÓMEZ, J. L. y CORREA, F. (2013): “O sonho da casa própria: um estudo comparado do crédito hipotecário em Argentina e Brasil na primeira metade do século XX". VII Congreso del Consejo Europeo de Investigaciones Sociales de América Latina, Universidad Fernando Pessoa, Oporto.

GÓMEZ, J. L. (2012): "Empresarios de la vivienda, el caso de F.I.N.C.A frente a las políticas del Banco Hipotecario Nacional entre 1936 y 1955", Anuario Centro de Estudios Económicos de la Empresa y los Empresarios, 4 (4), pp. 149-190. https://ojs.econ.uba.ar/index.php/CEEED/ article/view/1098.

GÓMEZ, J. L. y GILBERT, J. (2019): “Vivienda y Crédito en Argentina: evolución y dinámica del financiamiento habitacional entre 1936 y 1946", Anuario del Centro de Estudios Económicos de la Empresa y el Desarrollo, 11, pp. 165-206. https://ojs.econ.uba.ar/index.php/CEEED/ article/view/1452.

GÓMEZ, J. L. (2014): “La unión hace la fuerza. Las Compañías de Crédito Recíproco y el financiamiento hipotecario a bajo interés en Argentina, 1935-1949", Historia Económica e Historia de Empresas, XVII (2), pp. 443-473.

GRAVAGNUOLO, B. (2010): Historia del Urbanismo en Europa, Madrid, Akkal.

GUALINDO GUARNEROS, G. (1962): Las Instituciones de Ahorro y Préstamo para la Vivienda Familiar, México, Editorial Jus.

GUIDE, C. (1913): Las Instituciones de Progreso Social. México, Librería de la V. de Ch. Bourtet.

GUIDE, C. (1932): Curso de Economía Política, París, Lagny.

GUTIERREZ, R. (coord.) (2011): Sanchez, Lagos y De la Torre: del Eclecticismo al Modernismo, Buenos Aires, CEDODAL.

GUTIERREZ, R. y GUTMAN, G. (1988): Vivienda. Ideas y contradicciones, de las Casas Baratas a la Erradicación de las Villas de Emergencia. Resistencia, Instituto Argentino de Arquitectura y Urbanismo.

HARISPURU, A. y DOMÍNGUEZ, E. (2010): "Malestar urbano y 'ciudad jardín'. Una idea en desarrollo", XXII Jornadas de Historia Económica, Universidad Nacional de Río Cuarto, Córdoba.

HOBSBAWN, E. (1982): Las revoluciones bueguesas, Guardarrama, Barcelona.

HOBSBAWN, E. (2003): La era del Imperio, 1875-1914, Buenos Aires, Crítica.

IÓVINE, J. (1947): Sociedades de ahorro para la vivienda en la Argentina. Tesis doctoral, Buenos Aires, Universidad de Buenos Aires, Facultad de Ciencias Económicas, http://bibliotecadigital.econ.uba.ar/download/ tesis/1501-0440_lovineJA.pdf.

LAMAS, A. (1950): Ahorro y préstamo para la vivienda familiar, Buenos Aires, Fondo de Cultura Económica.

LANATA BRIONES, C. (2020): "Una nueva estimación del índice del costo de vida en Argentina, 1912-1932", Boletín del Instituto de Historia Argentina y Americana Dr. Emilio Ravignani, 53.

LANCIOTTI, N. (2009): De rentistas a empresarios. Inversión inmobiliaria y urbanización en la pampa argentina, Santa Fe, Universidad Nacional del Litoral.

LANCIOTTI, N. (2006): "El pequeño y mediano empresariado inmobiliario en las ciudades argentinas: Organización y prácticas de negocios, 1870-1914", Helsinki, World Economic History Congress. https://researchportal.helsinki.fi/en/activities/world-economic-history-congress-4. 
LANCIOTTI, N.; ABRAHAM, L.; BRIZUELA, F. y KOFMAN, M, (2020): “Mercado Inmobiliario en Rosario: Ciclos Económicos y Políticas Públicas, 19141966", Anuario del Centro de Estudios Económicos de la Empresa y el Desarrollo, 13, pp. 17-38.

LARROSA, L. (1947): El problema de la vivienda y el Estado, Tesis Doctoral, Universidad de Buenos Aires, Facultad de Ciencias Económicas, Buenos Aires.

LERCARI, J. (1945): La vivienda obrera, Tesis Doctoral, Universidad de Buenos Aires, Facultad de Ciencias Económicas, Buenos Aires.

LIERNUR, F. (2014): “El rol inicial del Estado. La Comisión Nacional de Casas Baratas". Ballent y Liernur. La casa y la multitud. Vivienda, Política y Cultura en la Argentina Moderna. Buenos Aires, Fondo de Cultura Económica.

LIERNUR, F. (1984): "Buenos Aires: la estrategia de la casa autoconstruida"., en Carlos Barrán (comp.), Sectores populares y vida urbana, Buenos Aires, CLACSO.

MARTíN, J. (1943): El Crédito Recíproco, Buenos Aires, Premier.

MARTíN, J. (1963): El Ahorro y préstamo. Fuente generadora de viviendas, Buenos Aires, Premier.

MASON, D. (2004): "The Ties that Bind: Mutual Building and Loans and the Problem of Agency, 1880-1920", Busines and Economic History, 2, https://thebhc.org/sites/default/files/Mason_0.pdf.

PARDO, A. (1947): Las sociedades de capitalización. Tesis Doctoral, Buenos Aires, Universidad de Buenos Aires. Facultad de Ciencias Económicas.

PEREZ, E. (1945): El Banco Hipotecario Nacional de 1933 a 1944, Buenos Aires, Imprenta López.

PEROTTI, E. (1943): La vivienda familiar, Buenos Aires, Construcciones Sudamericanas.

PEROTTI, E. (1944): Política de la Habitación. Sistemas y medios financieros para el Hogar Propio, Buenos Aires, El Ateneo editorial.

PESSAGNO, E. (1917): Los Bancos Hipotecarios en la República Argentina. Tesis Doctoral, Buenos Aires, Facultad de Ciencias Económicas, Universidad de Buenos Aires.

POLANYI, K. (2011): La Gran Transformación. Los orígenes económicos de nuestro tiempo, Fondo de Cultura Económica, Buenos Aires.

PRICE D. y WALTER J. (2019): "It's a Wonderful Loan: A Short History of Building and Loan Associations", Economic Brief, enero, https://www.richmondfed.org/publications/research/economic_brief/2019/eb_19-01.

PRICE. D. y WALTER. J. (2016): "Private Efforts for affordable mortage lending before Fannie and Fredie". Economic Quarterlyó, 102 (4). https:// www.richmondfed.org/publications/research/economic_quarterly/2016/q4/walter.
RADOVANOVIC, E. y BALMACEDA, C. (2011): La habitación popular bonaerense. Buenos Aires: CEDODAL.

REPPETO, N. (1976): Cómo nace y se desarrolla una cooperativa. Historia del Hogar Obrero, cooperativa de consumo, edificación y crédito, Ltda, Buenos Aires, Editora Cooperativa.

RIGOTTI, A. (2011): Viviendas para los trabajadores. Rosario, Prohistoria.

RONCHI, V. (2016): La cooperación integral. Historia del Hogar al obrero, Buenos Aires, Ediciones Fabro.

ROTTIN, L. (1950): El problema de la vivienda, Buenos Aires, Cámara Argentina de la Construcción, 1950.

SAMY, L. (2008): The Building Society promise. Building Societies and Home Ownership. Oxford, University of Oxford.

SCOBIE, J. (1977): Buenos Aires. Del Centro a los Barrios, 1870-1910, Buenos Aires, Ediciones del Solar.

SCOTT, P. (1996): The Property Masters. A History of the British Commercial Property Sector, Londres, Taylor and Francis.

SNOWDEN, K. (2003): "The Transition from Building and Loan to Savings and Loan, 1890- 1940". en Hoffman Engerman y Sokoloff Rosenthal (eds.), Finance, Intermediaries, and Economic Development, Nueva York, Cambridge University Press.

SURIANO, J. (1984): "La huelga de inquilinos de 1907 en Buenos Aires", en Sectores populares y vida urbana, Buenos Aires, CLACSO.

THOMPSON, E (2012): La formación de la clase obrera en Inglaterra. Madrir, Capitán Swing Libros.

TOPALOV, C. (1979): La Urbanización Capitalista, México, Edicol.

TOPALOV, C. (1984): Ganancias y rentas urbanas. Elementos teóricos, Buenos Aires, Siglo XXI.

WALTER, R. (1993): Politics and Urban Growth in Buenos Aires, 1910-1942, Londres, Cambridge University Press.

WELLINGS, F. (2006): Britihs housebuilders. History and analysis, Oxford, Blackwell.

WHITE, N.; SNOWDEN, K. y FISHBACK, P. V. (2014): Housing and mortage markets in historical perspective. Chicago, University of Chicago Press.

YUJNOVSKY, O. (1974): "Políticas de vivienda en la ciudad de Buenos Aires, 1880-1914", Desarrollo Económico, vol. 14, núm. 54.

YUJNOVSKY, O. (1984): Claves políticas del problema habitacional argentino, 1955-1981. Buenos Aires, Grupo Editor Latinoamericano.

ZEYEN, E. (1956): Memorias. Mimeo. 
Anexo Cuadros

Cuadro 1. Sociedades de Crédito Recíproco (año 1943)

\begin{tabular}{|c|c|c|c|}
\hline Nombre & Fecha de creación & Préstamos realizados en $\$$ & Jurisdicción \\
\hline ARCA & 04-07-1935 & 20.000 .000 a 02-1943 & Capital Federal \\
\hline FINCA & $29-02-1936$ & 6.378.349 a 02- 1943 & Capital Federal \\
\hline SUCA & 20-02-1937 & 4.893 .550 a $11-1942$ & Capital Federal \\
\hline LAR & 18-08-1939 & 414.500 a $11-1942$ & Capital Federal \\
\hline COFRE & $02-01-1940$ & 456.000 a 09-1942 & Capital Federal \\
\hline La Movilizadora & 03-03-1941 & 52.500 a $12-1941$ & Capital Federal \\
\hline FÁCIL & 09-10-1941 & Sin adjudicaciones & Capital Federal \\
\hline CIFRA & 31-03-1942 & 576.500 a 01-1943 & Capital Federal \\
\hline Independencia & 21-07-1942 & Sin adjudicaciones & Capital Federal \\
\hline COARLI & 01-02-1936 & 1.5000 .000 a $11-1942$ & Prov. Buenos Aires \\
\hline OPAL & 05-08-1938 & 2.748 .700 a $03-1942$ & Prov. Santa Fe \\
\hline La Comercial de Rosario & 01-12-1939 & Sin datos & Prov. Santa Fe \\
\hline Mi Hogar & 18-09-1939 & 158.500 a 05-1941 & Prov. Santa Fe \\
\hline Financiadora del Hogar & 21-08-1940 & 338-500 a 05-1942 & Prov. Santa Fe \\
\hline APMA & 03-01-1941 & Sin datos & Prov. Santa Fe \\
\hline Edificador Rosarino & 08-04-1941 & 972.500 a 02-1943 & Prov. Santa Fe \\
\hline
\end{tabular}

Fuente: elaboración propia en base Martín (1943). 